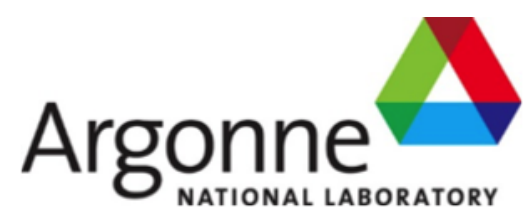

ANL-ART-137

\title{
Development of Grade 91 inelastic model for incorporation in ASME Division 5
}

Applied Materials Division 
About Argonne National Laboratory

Argonne is a U.S. Department of Energy laboratory managed by UChicago Argonne, LLC under contract DE-AC02-06CH11357. The Laboratory's main facility is outside Chicago, at 9700 South Cass Avenue, Argonne, Illinois 60439. For information about Argonne and its pioneering science and technology programs, see www.anl.gov.

\section{DOCUMENT AVAILABILITY}

Online Access: U.S. Department of Energy (DOE) reports produced after 1991 and a growing number of pre-1991 documents are available free at OSTI.GOV (http://www.osti.gov/), a service of the U.S. Dept. of Energy's Office of Scientific and Technical Information

Reports not in digital format may be purchased by the public from the

National Technical Information Service (NTIS):

U.S. Department of Commerce

National Technical Information Service

5301 Shawnee Rd

Alexandria, VA 22312

www.ntis.gov

Phone: (800) 553-NTIS (6847) or (703) 605-6000

Fax: (703) 605-6900

Email: orders@ntis.gov

Reports not in digital format are available to DOE and DOE contractors from the Office of Scientific and Technical Information (OSTI)

U.S. Department of Energy

Office of Scientific and Technical Information

P.O. Box 62

Oak Ridge, TN 37831-0062

www.osti.gov

Phone: (865) 576-8401

Fax: (865) 576-5728

Email: reports@osti.gov

\section{Disclaimer}

This report was prepared as an account of work sponsored by an agency of the United States Government. Neither the United States Government nor any agency thereof, nor UChicago Argonne, LLC, nor any of their employees or officers, makes any warranty, express or implied, or assumes any legal liability or responsibility for the accuracy, completeness, or usefulness of any information, apparatus, product, or process disclosed, or represents that its use would not infringe privately owned rights. Reference herein to any specific commercial product, process, or service by trade name, trademark, manufacturer, or otherwise, does not necessarily constitute or imply its endorsement, recommendation, or favoring by the United States Government or any agency thereof. The views and opinions of document authors expressed herein do not necessarily state or reflect those of the United States Government or any agency thereof, Argonne National Laboratory, or UChicago Argonne, LLC. 


\section{Development of Grade 91 inelastic model for incorporation in ASME Division 5}

Applied Materials Division

Argonne National Laboratory

July 2018

Prepared by

M. C. Messner, Argonne National Laboratory

V.-T. Phan, Argonne National Laboratory

T.-L. Sham, Argonne National Laboratory 



\section{Abstract}

This report describes a unified viscoplastic model for Grade 91 suitable for use with the Section III, Division 5 design by inelastic analysis procedures in the ASME Boiler and Pressure Vessel Code. The report identifies several key features a successful design inelastic model must capture along with critical aspects of the response of Grade 91 for elevated temperature loading conditions typical of expected reactor operating conditions. An inelastic model for Code design must capture the average response of a material including heat-to-heat and product form variations. This work develops a method for calibrating such a model to a large experimental database using genetic algorithm optimization. Finally, the report compares the final model to several specialized experimental tests to validate that it will be suitable for use in high temperature structural design. The techniques developed here can be applied to the remaining Section III, Division 5, Class A materials to develop a nonmandatory appendix to the Code describing inelastic material models suitable for use with the design by inelastic analysis procedures. 



\section{Table of Contents}

Abstract

Table of Contents $\quad$ iii

List of Figures $\quad$ V

List of Tables vii

1 Introduction 1

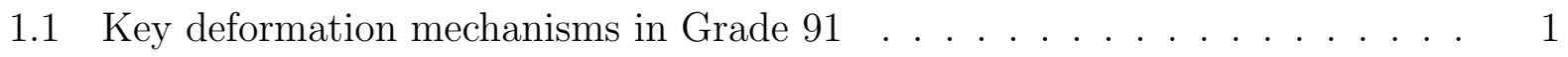

1.2 Key features of an inelastic model for Section III, Division 5 design . . . . . 2

1.3 Overview . . . . . . . . . . . . . . . . . . . 2

2 Model form 5

2.1 Continuum Equations . . . . . . . . . . . . . . . . . 5

2.1.1 Rate sensitivity . . . . . . . . . . . . . . . . 5

2.1.2 Cyclic softening . . . . . . . . . . . . . . . . . . . . 8

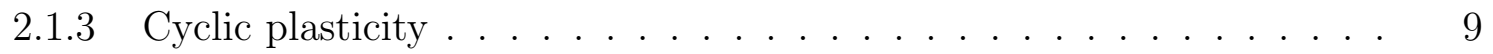

2.1.4 Tertiary creep . . . . . . . . . . . . . . . . . . . 9

2.1.5 Anomalous ratcheting . . . . . . . . . . . . . . . . 10

2.2 Discrete update equations . . . . . . . . . . . . . . . . . . . 11

3 Calibrating the model parameters 13

3.1 Experimental data . . . . . . . . . . . . . . . . . . . . . . . . . . . . . . . . . . . 13

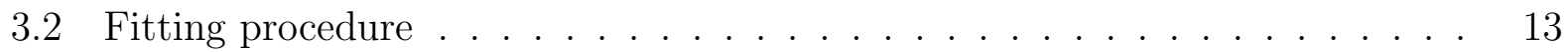

3.3 Basic mechanical response of the model . . . . . . . . . . . . . . . 17

4 Model validation 31

4.1 Batch and product form variation . . . . . . . . . . . . . . 31

4.2 Temperature variation . . . . . . . . . . . . . . . . . . . . . . . . . . . . . . . . . . . . .

4.3 Long term creep . . . . . . . . . . . . . . . . . . . . . . . . . . . . . . . . . . . . . . . . . . . . .

4.4 Creep-fatigue loading . . . . . . . . . . . . . . . . . . . . . . . . . . . . . . . . . . . . . . 33

4.5 Anomalous ratcheting . . . . . . . . . . . . . . . . . 34

5 Conclusions 39

Acknowledgments $\quad 41$

Bibliography $\quad 43$

$\begin{array}{ll}\text { Distribution List } & 47\end{array}$ 



\section{List of Figures}

2.1 Kocks-Mecking master diagram for Grade 91, using the experimental data summarized in Chapter 3. . . . . . . . . . . . . . . . . . .

2.2 Schematic showing the pameters used to define the Kocks-Mecking flow stress model ................................ 7

2.3 Ratcheting data from Yaguchi and Takahashi [36] showing anomalous ratcheting under fully-reversed stress controlled load. . . . . . . . . . . . . . . 10

2.4 Tension/compression tests reported in Yaguchi and Takahashi [36]. . . . . . 11

3.1 Model flow curves at $T=25^{\circ} \mathrm{C}$ as a function of increasing strain rate. . . . 18

3.2 Model flow curves at $T=100^{\circ} \mathrm{C}$ as a function of increasing strain rate. . . . 18

3.3 Model flow curves at $T=200^{\circ} \mathrm{C}$ as a function of increasing strain rate. . . . 18

3.4 Model flow curves at $T=300^{\circ} \mathrm{C}$ as a function of increasing strain rate. . . . 19

3.5 Model flow curves at $T=400^{\circ} \mathrm{C}$ as a function of increasing strain rate. . . . 19

3.6 Model flow curves at $T=500^{\circ} \mathrm{C}$ as a function of increasing strain rate. . . . 19

3.7 Model flow curves at $T=550^{\circ} \mathrm{C}$ as a function of increasing strain rate. . . . 20

3.8 Model flow curves at $T=600^{\circ} \mathrm{C}$ as a function of increasing strain rate. . . . 20

3.9 Model flow curves at $T=650^{\circ} \mathrm{C}$ as a function of increasing strain rate. . . . 20

3.10 Model flow curves as a function of increasing temperature (in ${ }^{\circ} \mathrm{C}$ ) at fixed strain rate. . . . . . . . . . . . . . . . . . . . . . 21

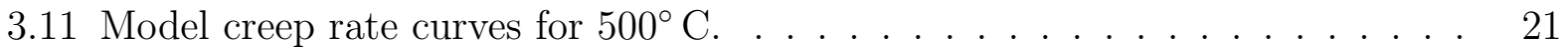

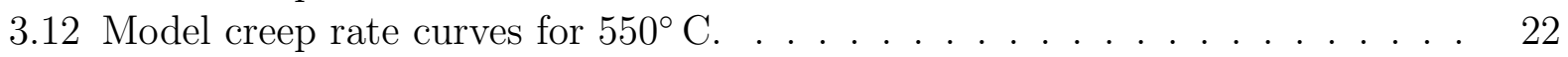

3.13 Model creep rate curves for $600^{\circ} \mathrm{C}$. . . . . . . . . . . . . . . . . 22

3.14 Model creep rate curves for $650^{\circ}$ C . . . . . . . . . . . . . . . . . . . . 22

3.15 Comparison between model and experiment for uniaxial tension tests at $T=$ $25^{\circ} \mathrm{C}$.

3.16 Comparison between model and experiment for strain controlled cyclic tests at $T=25^{\circ}$ C . . . . . . . . . . . . . . . . . . . .

3.17 Comparison between model and experiment for uniaxial tension tests at $T=$

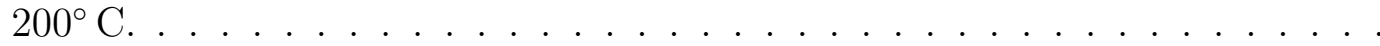

3.18 Comparison between model and experiment for uniaxial tension tests at $T=$

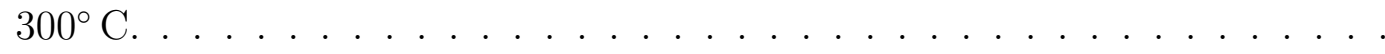

3.19 Comparison between model and experiment for uniaxial tension tests at $T=$ $400^{\circ}$ C . . . . . . . . . . . . . . . . . .

3.20 Comparison between model and experiment for stress relaxation tests at $T=$

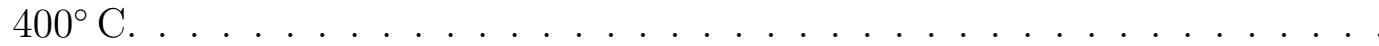

3.21 Comparison between model and experiment for uniaxial tension tests at $T=$ $500^{\circ}$ C . . . . . . . . . . . . . . . . . . 26

3.22 Comparison between model and experiment for creep tests at $T=500^{\circ} \mathrm{C}$. . $\quad 26$

3.23 Comparison between model and experiment for stress relaxation tests at $T=$

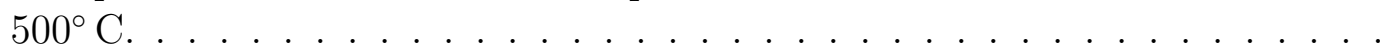

3.24 Comparison between model and experiment for strain controlled cyclic tests at $T=500^{\circ} \mathrm{C} \ldots \ldots \ldots \ldots \ldots \ldots$

3.25 Comparison between model and experiment for uniaxial tension tests at $T=$ $550^{\circ} \mathrm{C}$. 
3.26 Comparison between model and experiment for creep tests at $T=550^{\circ} \mathrm{C}$. .

3.27 Comparison between model and experiment for stress relaxation tests at $T=$

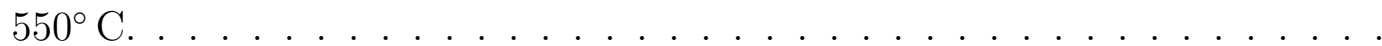

3.28 Comparison between model and experiment for strain controlled cyclic tests at $T=550^{\circ}$ C . . . . . . . . . . . . . . . . . . . . 28

3.29 Comparison between model and experiment for creep tests at $T=575^{\circ} \mathrm{C} . .28$

3.30 Comparison between model and experiment for uniaxial tension tests at $T=$ $600^{\circ}$ C . . . . . . . . . . . . . . . . . . . 29

3.31 Comparison between model and experiment for creep tests at $T=600^{\circ} \mathrm{C}$. . .

3.32 Comparison between model and experiment for stress relaxation tests at $T=$

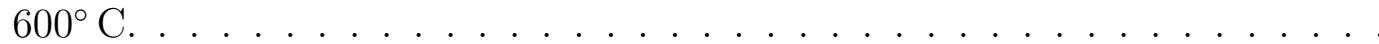

3.33 Comparison between model and experiment for strain controlled cyclic tests at $T=600^{\circ}$ C . . . . . . . . . . . . . . . . . .

3.34 Comparison between model and experiment for uniaxial tension tests at $T=$ $650^{\circ}$ C . . . . . . . . . . . . . . . . . 30

3.35 Comparison between model and experiment for creep tests at $T=650^{\circ} \mathrm{C} . . \quad 30$

4.1 Model prediction for the material yield stress as a function of temperature (solid line) plotted with the data underlying the ASME Code values of yield stress $S_{y}$ (points). . . . . . . . . . . . . . .

4.2 Comparison between the results of a thermomechanical test on a Grade 91 sample and corresponding simulation predictions. . . . . . . . . . . .

4.3 Comparison between the results of a thermomechanical test on a Grade 91 sample and corresponding simulation predictions. . . . . . . . . . . .

4.4 Comparison between model (solid) and Code (dashed) isochronous stressstrain curves at $500^{\circ} \mathrm{C}$. From top to bottom and blue to red colors the curves are for $1,10,100,1,000,10,000,100,000$, and 300,000 hours. . . . . . . . .

4.5 Comparison between model (solid) and Code (dashed) isochronous stressstrain curves at $550^{\circ} \mathrm{C}$. From top to bottom and blue to red colors the curves are for 1, 10, 100, 1,000, 10,000,100,000, and 300,000 hours. . . . . . . . .

4.6 Comparison between model (solid) and Code (dashed) isochronous stressstrain curves at $600^{\circ} \mathrm{C}$. From top to bottom and blue to red colors the curves are for 1, 10, 100,1,000,10,000,100,000, and 300,000 hours. . . . . . . . .

4.7 Comparison between model (solid) and Code (dashed) isochronous stressstrain curves at $650^{\circ} \mathrm{C}$. From top to bottom and blue to red colors the curves are for 1, 10, 100,1,000,10,000, 100,000, and 300,000 hours. . . . . . . . .

4.8 Comparison between model (black) and experiment (red) for a creep-fatigue

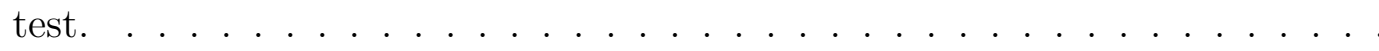

4.9 Comparison between model (solid) and experiment (dashed) for several stress controlled cyclic tests with various $R$ ratios. . . . . . . . . . . . . 


\section{List of Tables}

3.1 Table summarizing the sources of experimental data used to calibrated the Grade 91 inelastic model . . . . . . . . . . . . . . . . . . . . . . . 14

3.2 Table of elastic and thermal properties for the Grade 91 model. These properties are taken directly from Section III, Division 5 of the ASME Code [1]. . 15

3.3 Physical constants used in the Kocks-Mecking model. . . . . . . . . . . . . . 15

3.4 Calibrated material properties for the Kocks-Mecking rate sensitivity model . 15

3.5 Hyperparameters used in the genetic algorithm optimization scheme. . . . . 16

3.6 Material properties calibrated with the GA optimization scheme . . . . . . 17 



\section{Introduction}

This report describes a unified viscplastic model for Grade 91 steel suitable for use with the design by inelastic analysis method described in Section III, Division 5 of the ASME Boiler and Pressure Vessel Code [2]. The ultimate goal of this work is to establish reference inelastic models that can be used for design with the inelastic provisions and collect these models in a nonmandatory appendix to the Code.

Grade 91 is a ferritic-martensitic steel with excellent high temperature strength, good thermal conductivity, and low thermal expansion. It was originally developed as part of the Clinch River Breeder Reactor Project and its mechanical and thermal properties make it an excellent potential material for sodium heat exchangers. However, there are several modeling challenges posed by Grade 91's complex microstructure. This report describes an inelastic model that captures the average response of Grade 91 steel, as collated in a large collection of experimental data on various heats and product forms.

\subsection{Key deformation mechanisms in Grade 91}

Grade 91 has a metastable initial microstructure consisting of large prior austenite grains with an embedded, complex subgrain structure consisting of packets of material that followed the same FCC to BCC transition and, within each packet, lath and sublath grain substructure. The lath and sublaths can be regarded as a ordered dislocation structure, rather than as strong, high-angle grain boundaries. This structure changes under elevated temperature loading, significantly affecting the properties of the material in elevated temperature service.

One consequence of this initial structure is that Grade 91 is highly rate sensitive, even at relatively low temperatures. This means plastic deformation and creep are intrinsically coupled — prior plasticity significantly affects subsequent creep and vice-versa. Modeling this type of coupled plastic-creep deformation requires a unified viscoplastic model. However, at low temperatures typical of plant shutdown conditions Grade 91 has a substantially rateindependent plastic response. The final model developed here accounts for both deformation regimes and consistently models the transition between a rate independent and a unified viscoplastic response.

Another consequence of Grade 91's as-received microstructure is that the material undergoes cyclic and even monotonic softening at elevated temperatures. At moderate temperatures under cyclic loading the material flow stress decreases rather than increases, as is typical, for example, in austenitic stainless steels. Similarly, at high temperatures the material's monotonic flow stress decreases with increasing deformation. Both effects are caused by dislocation recovery from the high density, metastable initial structure.

A final consequence of the material's complicated microstructure is tension/compression asymmetry and anomalous ratcheting. The material flow stress in the compression direction is slightly higher than the flow stress in the tensile direction. For monotonic loading this difference in flow stress is essentially negligible. However, under cyclic loading these small differences accumulate to cause anomalous ratcheting: the material ratchets in the tensile direction even under fully-reversed stress controlled loading. 


\subsection{Key features of an inelastic model for Section III, Division 5 design}

There are several previous models for Grade 91 in the literature [22, 35]. However, these models attempt to represent a single batch of material and a single product form. Developing a material model used for Section III, Division 5 design is substantially more challenging as it must represent the average behavior of the material as a whole, including heat-to-heat and product form variation. This report describes a method for systematically calibrating a model to meet this criterion by using genetic algorithmic optimization to calibrate the model parameters to match the average response of a large collection of experimental data collected for various material heats and product forms. Design factors in the creep-fatigue design process provide adequate margin against structural failure, starting from the assumption that the model describes an average material response. The Code ratcheting criteria are framed in terms of an average response. The criteria are formulated to provide an adequate margin if the material ratchets faster than the average response.

In addition to the change in rate sensitivity mentioned above the general hardening/softening response of the material changes as a function of temperature. A model used in design must capture this temperature variation, at least over the range of operating temperatures in future high temperature reactors. This report describes a model calibrated for a temperature range spanning from room temperature to $650^{\circ} \mathrm{C}$, which covers the Section III, Division 5 Class A use temperature range for the material.

The Grade 91 material model must accurately capture both the material's long term creep response - to accurately model the material stress state during long holds at operating conditions - and also material stress relaxation over shorter time scales, in order to accurately model creep damage in creep-fatigue loading. This means the model form must account for both long term creep and shorter term cyclic creep-plasticity.

Finally, a design inelastic model must capture the anomalous ratcheting behavior described previously. Section III, Division 5 design by inelastic analysis directly uses the ratcheting strains from a full inelastic simulation to design structures against ratcheting strain accumulation. Therefore, these ratcheting strains must include material ratcheting effects, like anomalous ratcheting, in addition to structural ratcheting effects.

\subsection{Overview}

Chapter 2 of this report describes the form used for the inelastic model. The model uses a method for representing rate sensitivity and the transition between a rate sensitive and rate independent plastic response based on the work of Kocks and Mecking [20, 21, 29]. A softening Voce isotropic term captures material softening and Chaboche kinematic hardening $[5,7-12]$ captures the material's cyclic plasticity response. A non- $J_{2}$ flow rule accounts for anomalous ratcheting.

Chapter 3 describes calibrating the material model parameters to a large collection of experimental data using genetic algorithm optimization. This process ensures that the material model matches the average response of Grade 91 as represented by the experimental database. Chapter 4 then validates the model against several more complicated experimental tests, including creep-fatigue, thermomechanical, and long-term creep data. The final chapter summarizes the conclusions of the report and discusses how the methods and 
Development of Grade 91 inelastic model for incorporation in ASME Division 5

July 2018

tools developed for Grade 91 could be applied to the other Section III, Division 5 Class A materials. 



\section{Model form}

The inelastic model must be capable of representing the key deformation mechanisms identified in the introduction. While ultimately the numerical model is tightly coupled - each feature of the model affects the overall model response - conceptually this chapter associates a particular model feature with a particular deformation mechanism. This organization reflects our process in developing the model and provides some background on how each feature of the model was selected.

\subsection{Continuum Equations}

The general form of the model is a non-associative inelastic material model including the contribution of thermal strain. The model divides the total strain rate into elastic, inelastic, and thermal contributions:

$$
\dot{\varepsilon}=\dot{\varepsilon}_{\text {elastic }}+\dot{\varepsilon}_{\text {inelastic }}+\dot{\varepsilon}_{\text {thermal }} .
$$

The elastic strain rate linearly relates to the stress rate through a temperature-dependent elasticity tensor $\mathbf{C}$, which is defined here using the temperature-dependent elastic constants $E$ and $\nu$ in Section II of the ASME Code:

$$
\dot{\varepsilon}_{\text {elastic }}=\mathrm{C}^{-1} \cdot \dot{\boldsymbol{\sigma}} .
$$

The thermal strains are defined by the instantaneous coefficient of thermal expansion $\alpha$, similarly taken from Section II of the Code

$$
\dot{\varepsilon}_{\text {thermal }}=\alpha \dot{T} \mathbf{I}
$$

where $\dot{T}$ is the temperature rate and $\mathbf{I}$ is the identity tensor. Combining equations 2.1-2.3 gives the ordinary differential equation

$$
\dot{\boldsymbol{\sigma}}=\mathbf{C}:\left(\dot{\boldsymbol{\varepsilon}}-\dot{\boldsymbol{\varepsilon}}_{\text {inelastic }}-\alpha \dot{T} \mathbf{I}\right)
$$

Given some strain history $\varepsilon(t)$ and temperature history $T(t)$ the goal of the model is to predict the stress history $\sigma(t)$. The only remaining undefined component of the model is the inelastic strains $\dot{\varepsilon}_{\text {inelastic }}$. The remainder of this chapter focuses on defining an appropriate model for inelastic deformation.

\subsubsection{Rate sensitivity}

The inelastic model must accommodate the transition from rate independent deformation at low temperatures to rate dependent plastic flow at higher temperatures. The form of the stress update - the definition of the inelastic strain rate - is very different for the two types of behavior yet the two are tightly coupled - prior rate independent plastic deformation affects later rate dependent deformation at higher temperatures and vice versa.

The first task is to delineate the rate independent and rate dependent regimes. To do this we use a model developed by Kocks and Mecking [19-21, 28, 29]. Essentially, they posit a model for the material flow stress as a function of normalized activation energy

$$
g=\frac{k T}{\mu b^{3}} \log \left(\frac{\dot{\varepsilon}_{0}}{\dot{\varepsilon}_{\text {inelastic }}}\right)
$$




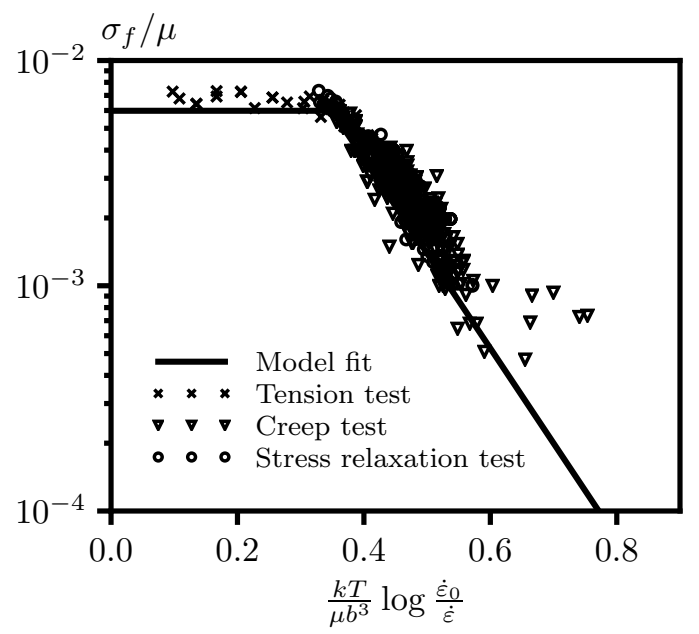

Figure 2.1: Kocks-Mecking master diagram for Grade 91, using the experimental data summarized in Chapter 3.

where $k$ is the Boltzmann constant, $\mu$ the material shear modulus, $b$ the Burgers vector length, $\dot{\varepsilon}_{0}$ a reference strain rate, and $\dot{\varepsilon}_{\text {inelastic }}$ is an equivalent, scalar inelastic strain rate. In this equation $T$ must be an absolute temperature and $\log$ is a natural logarithm.

Figure 2.1 shows a Kocks-Mecking diagram for Grade 91, using experimental data described in detail in Chapter 3. A Kocks-Mecking diagram plots the log of the material flow stress, normalized by the temperature dependent shear modulus, versus the normalized activation energy. This diagram plots data from experiments measuring the material flow stress in the as-received condition. It uses data from three types of experiments: uniaxial, monotonic tension tests, creep tests, and stress relaxation tests. Each type of experiment requires some post-processing to convert the data into the Kocks-Mecking form:

Tension tests Test temperature and strain rate are controlled. Use the measured yield stress to represent the initial flow stress.

Creep tests The test temperature and the material flow stress are controlled. Use the initial rate of primary creep as representative of the material in the as-received condition.

Stress relaxation tests The test temperature is controlled. A stress relaxation test occurs at fixed strain. Therefore the rate of inelastic and elastic strains must be equal and opposite to maintain a zero total strain rate. The stress relaxation history is measured in the experiment. This stress relaxation history can be numerically differentiated to get the stress rate. The rate of inelastic strain is then $\dot{\varepsilon}_{\text {inelastic }}=-\dot{\sigma} / E$. A stress relaxation test then gives a line on the Kocks-Mecking diagram corresponding to the measured experimental stress relaxation curve. Figure $2.1 \mathrm{rep}-$ resents this line with 10 points for each stress relaxation test.

The Kocks-Mecking model shown in Fig. 2.1 gives a model for the initial flow stress as a function of temperature and strain rate. The bilinear form of the curve is typical for many 


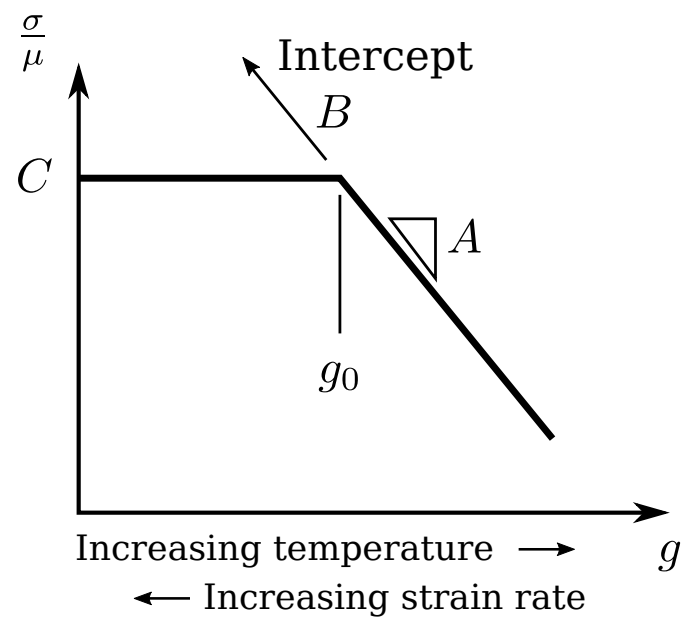

Figure 2.2: Schematic showing the pameters used to define the Kocks-Mecking flow stress model

structural materials. The horizontal part of the curve in the high strain rate, low temperature regime represents rate independent inelastic deformation - temperature and strain rate do not affect the material flow stress. The linear portion of the curve then represents rate dependent deformation.

The Kocks-Mecking approach to modeling the flow stress has the advantage of being physically-based. The Kocks-Mecking normalized activation energy describes the amount of thermal energy available for a dislocation to use to overcome barriers to slip.

A Kocks-Mecking diagram can be turned into a method for determining whether a model should take a rate independent or rate dependent step and then also to determine the yield stress or rate sensitivity parameters for the stress update. Figure 2.2 shows a simplified schematic of a bilinear Kocks-Mecking model for the initial flow stress defining the parameters $A, B, C$, and $g_{0}$. The next chapter describes how to fit these parameters from experimental data.

The model uses $g_{0}$ to select the type of update:

$$
\dot{\varepsilon}_{\text {inelastic }}= \begin{cases}\dot{\varepsilon}_{r i} & g \leq g_{0} \\ \dot{\varepsilon}_{r d} & g>g_{0}\end{cases}
$$

where subscript $r i$ refers to a rate independent step and $r d$ refers to a rate dependent step. The two updates are defined by the equations

$$
\begin{aligned}
\dot{\boldsymbol{\varepsilon}}_{r i} & =\gamma \frac{\partial f}{\partial \boldsymbol{\sigma}} \\
\gamma & \geq 0 \\
f(\boldsymbol{\sigma}) & \leq 0 \\
\gamma f(\boldsymbol{\sigma}) & =0 \\
\gamma \dot{f}(\boldsymbol{\sigma}) & =0
\end{aligned}
$$


and

$$
\begin{array}{rrr}
\dot{\varepsilon}_{r d} & = & \dot{\gamma} \frac{\partial f}{\partial \boldsymbol{\sigma}} \\
\dot{\gamma} & = & \frac{\langle f(\boldsymbol{\sigma})\rangle^{n}}{\eta} \\
\sigma_{f} & = & \sigma_{i s o} \\
n & = & -\frac{\mu b^{3}}{k T A} \\
\eta & e^{B} \mu \dot{\varepsilon}_{0}^{k T A /\left(\mu b^{3}\right)} .
\end{array}
$$

In these equations $f$ is a flow function, \langle\rangle are the Macaulay brackets, and the remaining parameters are defined through the Kocks-Mecking model. Both models use

$$
f(\boldsymbol{\sigma})=L(\boldsymbol{\sigma}-\boldsymbol{x})-\sqrt{\frac{2}{3}}\left(\sigma_{0}+\sigma_{1}\right)
$$

where $L, \boldsymbol{x}$, and $\sigma_{1}$ are defined below. $\sigma_{0}$ is the offset stress, defined differently for the rate independent and rate dependent updates:

$$
\sigma_{0}= \begin{cases}\mu e^{C} & g \leq g_{0} \\ 0 & g>g_{0} .\end{cases}
$$

For the rate dependent update the rate sensitivity parameters provide the correct values of the initial flow stress. The rate independent update uses $\sigma_{0}$ to set the initial yield stress.

The Kocks-Mecking model predicts that the material rate sensitivity depends on both the temperature and strain rate. Higher temperatures and slower strain rates will trigger a rate dependent step; lower temperatures and faster strain rates will trigger a rate independent step. This relates to the underlying material physics. At slower strain rates dislocations have more time to sit at obstacles and it is more likely that random thermal fluctuations will enable the dislocation to move past the obstacle. This behavior also ensure that the model will capture creep deformation at all temperatures as a slower strain rate will trigger a rate dependent response.

The remainder of the model is the same for both the rate independent and rate dependent updates. Note that the model, thus far, has not defined any history variables to evolve the flow stress and all history variables have identical definitions in both types of updates. This ensures that the model consistently tracks the evolution of the flow stress, accounting for prior material history whether it was generated in the rate independent or rate dependent regimes.

\subsubsection{Cyclic softening}

The introduction identified cyclic and work softening as critical features to capture in a model for the constitutive response of Grade 91. The model uses the isotropic hardening/softening portion of the model, $\sigma_{1}$, to capture this behavior. The model uses a Voce softening model 
to represent both work and cyclic hardening, at low temperatures, and work and cyclic softening, at high temperatures:

$$
\dot{\sigma}_{1}=\delta\left(\sigma_{1}-Q\right) \gamma
$$

where $\delta$ and $Q$ are both temperature-dependent material parameters. This definition makes $\sigma_{1}$ the first of several history variables determining the flow stress of the material as a function of prior deformation history.

In this equation $Q$ is the saturated value of the isotropic part of the flow rule. If $Q>0$ it describes cyclic and work hardening or if $Q<0$ it describes cyclic and flow softening. This model can then accommodate both the low and high temperature experimental behavior of Grade 91.

\subsubsection{Cyclic plasticity}

Under stress-controlled loading isotropic hardening or softening models an increase or decrease in the height of the stress/strain hysteresis loop. Kinematic hardening models a shift in the center of the hysteresis loop. Accurately capturing this shift is critical for modeling ratcheting strain accumulation in structures, which is one of the main objectives for a inelastic constitutive model used for high temperature design. Kinematic hardening is modeled with the backstress $\boldsymbol{x}$ in Eq. 2.17. A model for cyclic plasticity then is a set of evolution equations for this kinematic hardening backstress.

There are several competing modeling approaches in widespread use for elevated temperature cyclic plasticity including frameworks developed by Ohno and Wang [30, 31] and Krempl [24, 25, 33]. We elect to use what is probably the most widely used kinematic hardening framework, developed by Chaboche $[5-7,9,11,12]$. In its simplest form it is a generalization of the classic Frederick and Armstrong model [16].

$$
\begin{aligned}
\boldsymbol{x} & =\sum_{i=1}^{n} \boldsymbol{x}_{i} \\
\dot{\boldsymbol{x}}_{i} & =\left(\frac{2}{3} C_{i} \frac{\partial f}{\partial \boldsymbol{\sigma}}-\sqrt{\frac{2}{3}} \gamma_{i} \boldsymbol{x}_{i}\right) \dot{\gamma}
\end{aligned}
$$

where $n$ is the number of backstresses, $C_{i}$ and $\gamma_{i}$ are temperature dependent material constants. Each backstress introduces a tensor, stress-like history variable into the formulation.

The basic Chaboche model can, with sufficient backstresses, predict the evolution of cyclic plasticity hysteresis as the stress-strain hysteresis loop evolves to some steady state as inelastic deformation progresses. This basic model does not predict any change in the flow stress under static conditions.

\subsubsection{Tertiary creep}

A common extension to the base Chaboche model is to add a term to model static recovery - a reduction in the backstress at static conditions caused by purely thermal recovery mechanisms. The final model for Grade 91 uses this full Chaboche form, including the static 


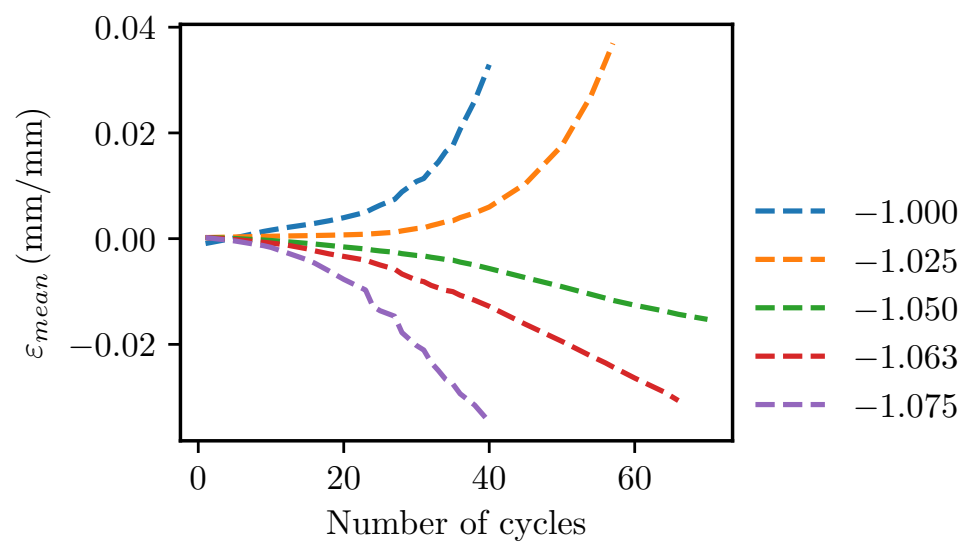

Figure 2.3: Ratcheting data from Yaguchi and Takahashi [36] showing anomalous ratcheting under fully-reversed stress controlled load.

recovery terms:

$$
\begin{aligned}
& \boldsymbol{x}= \\
& \dot{\boldsymbol{x}}_{i}=\left(\frac{2}{3} C_{i} \frac{\partial f}{\partial \boldsymbol{\sigma}}-\sqrt{\frac{2}{3}} \gamma_{i} \boldsymbol{x}_{i}\right) \dot{\gamma}-A_{i} \sqrt{\frac{3}{2}}\left\|\boldsymbol{x}_{i}\right\|^{a_{i}-1}
\end{aligned}
$$

where $A_{i}$ and $a_{i}$ are parameters describing static recovery and \|\| denotes the 2 -norm.

Without the static recovery terms the model predicts only primary and secondary creep. That is, the creep rate in the material under constant load decreases and saturates to some constant value. The static recovery terms provide a mechanism for an accelerating creep rate at long times at high temperatures.

\subsubsection{Anomalous ratcheting}

Figure 2.3 shows results of a ratcheting experiment by Yaguchi and Takahashi [36] on Grade 91. This test plots the mean strain — the center of the hysteresis loop — as a function of cycle number for stress controlled loading at several different $R$ ratios, where

$$
R=\frac{\sigma_{\min }}{\sigma_{\max }}
$$

Under fully-reversed loading $(R=-1.0)$ Grade 91 ratchets - the stress-strain hysteresis loop moves in the tensile direction. This is anomalous behavior as under fully-reversed loading the material strain should be symmetric and there should be no ratcheting. While this anomalous ratcheting is most obvious for fully reversed loading it affects the ratcheting response of the material for any loading ratio.

Figure 2.4 explains the cause of this anomalous ratcheting. This figure shows the results from a tension and compression test by Yaguchi and Takahashi [36] under the same loading 


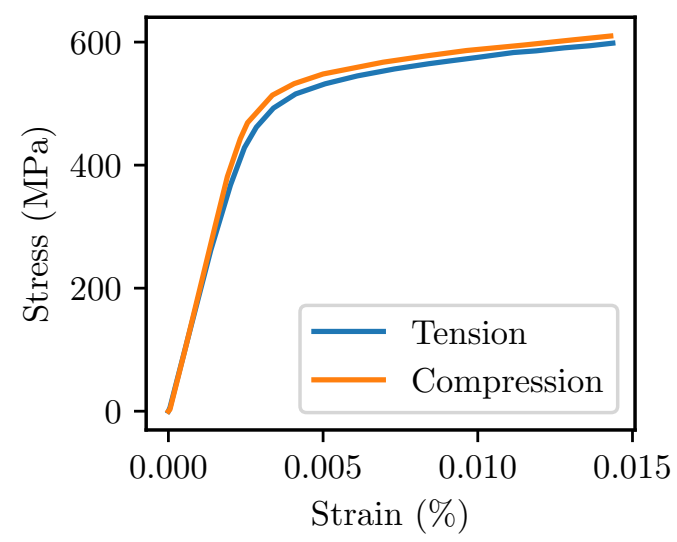

Figure 2.4: Tension/compression tests reported in Yaguchi and Takahashi [36].

conditions - only the direction of load is different. The two stress-strain curves show a slight tension-compression asymmetry - the flow stress in the compression direction is slightly higher than in the tension direction. This tension-compression asymmetry explains anomalous ratcheting. The small differences in tension and compression flow stress cause a shift in accumulated inelastic strain on each leg of the load cycle under fully-reversed load, causing the material to ratchet in the tensile direction.

The final model accounts for this anomalous ratcheting through the flow function, defined by the function $L$ above. A standard material model would use a $J_{2}$ flow theory where $L(\boldsymbol{\sigma})=J_{2}(\boldsymbol{\sigma})$. This type of model would not predict ratcheting under fully-reversed load.

Instead we use a flow function developed by Yaguchi [37] specifically to account for tension/compression asymmetry and ratcheting in Grade 91. The flow function takes the form

$$
L(\boldsymbol{\sigma})=\|\boldsymbol{s}-\boldsymbol{x}\|-h \operatorname{sign}(p) p^{l}
$$

where $\boldsymbol{s}$ is the deviatoric stress, $p=\operatorname{tr}(\boldsymbol{\sigma})$, and $h$ and $l$ are temperature dependent material parameters which can be calibrated to match experimentally-observed tension/compression asymmetry.

Not counting the elastic and thermal properties, this model has 15 constants at a fixed temperature. A complete, temperature dependent model must define these constants as a function of temperature.

\subsection{Discrete update equations}

The numerical implementation of the model is a fully-implicit integration of Eq. 2.4, which in turn invokes Eqs. 2.6, 2.11, 2.16, 2.17, 2.19, and 2.23. The form of the numerical model is

$$
\begin{aligned}
\boldsymbol{\sigma}_{n+1} & =\hat{\boldsymbol{\sigma}}_{n+1}\left(\boldsymbol{\varepsilon}_{n+1}, \boldsymbol{\varepsilon}_{n}, T_{n+1}, T_{n}, t_{n+1}, t_{n}, \boldsymbol{\sigma}_{n}, \boldsymbol{h}_{n}\right) \\
\boldsymbol{h}_{n+1} & =\hat{\boldsymbol{h}}_{n+1}\left(\boldsymbol{\varepsilon}_{n+1}, \boldsymbol{\varepsilon}_{n}, T_{n+1}, T_{n}, t_{n+1}, t_{n}, \boldsymbol{\sigma}_{n}, \boldsymbol{h}_{n}\right)
\end{aligned}
$$


where subscript $n+1$ are quantities at the next timestep and subscript $n$ indicates quantities at the previous time step. Here $\boldsymbol{h}$ is the total set of history vectors, i.e. the vector concatenating the isotropic term $\sigma_{i s o}$ and the backstresses $\boldsymbol{x}_{i}$. The model then requires strain, temperature, and time information for the next timestep and returns the updated stresses and history variables. This is the typical form for integration into finite element simulations.

The fully-implicit coupled integration of Eqs. 2.26 and 2.27 requires the Jacobian of those equations with respect to both the stress and history. Additionally, integration into an implicit finite element framework requires the algorithmic tangent

$$
\mathbf{A}_{n+1}=\frac{d \hat{\boldsymbol{\sigma}}_{n+1}}{d \boldsymbol{\varepsilon}_{n+1}} .
$$

The implementation of the model used in this report uses the exact form of all these derivatives, ensuring the implementation achieves optimal convergence. 


\section{Calibrating the model parameters}

\subsection{Experimental data}

This chapter describes how we fit the model parameters described in Chapter 2. The first task is to establish a database of experimental results to use in calibrating the model.

Table 3.1 summarizes the sources of data used to fit the model. In general, the calibration data falls into one of several types of standard tests:

1. Monotonic tension tests at controlled temperature and controlled strain rate or stroke displacement rate.

2. Creep tests at fixed load and temperature.

3. Stress relaxation tests at fixed strain and temperature.

4. Strain controlled tests (fatigue tests) with fixed temperature, maximum and minimum strain, and strain rate.

5. Stress controlled tests (ratcheting) with fixed temperature, maximum and minimum stress, and stress rate.

An effort was made to collect metadata describing the test conditions. However, some data required to fully define the testing conditions was not commonly reported. For example, the initial loading rate was not reported for creep tests. Reasonable assumptions were made to fill in for missing data.

Overall, the experimental database contains data from 463 experiments collected from a wide variety of sources and for a number of different batches of Grade 91 material.

\subsection{Fitting procedure}

We can divide the model properties into three categories:

1. Properties that can be established from reference data.

2. Properties that can be fit with standard regression techniques.

3. Properties that must be fit through sophisticated optimization methods.

The model elastic and thermal properties fall into the first category. These parameters can be directly taken from Section II of the ASME Code. These properties are temperature dependent. The Code tables provides finely granular data. In between these points the model linearly interpolates the parameters. Table 3.2 lists the model elastic and thermal properties, extracted directly from the Code.

Note all the parameters in this report are given in units consistent with the system defined by megapascals of stress, millimeters of distance, and seconds of time. In this system of units energy is expressed in millijoules, force in newtons, and mass in tonnes. Temperature dependent parameters are provided as functions of relative temperature, degrees Celsius. 


\begin{tabular}{ll}
\hline Source & Test types \\
\hline Asayama and Tachibana[3] & Creep, stress relaxation \\
Choudhary and Isaac Samuel [13] & Creep \\
Kim and Weertman [17] & Monotonic, cyclic \\
Kimura, Kushima, and Sawada[18] & Creep \\
Koo, Lee, and Kwon [22, 23] & Cyclic, stress relaxation \\
Latha et al. [26] & Monotonic, creep \\
Maruyama et al. [27] & Creep \\
Swindeman [32] & Monotonic \\
Yaguchi and Takahashi [35-37] & Monotonic, stress relaxation, cyclic \\
Zhang and Aktaa [38] & Cyclic \\
Archived DOE reports & All types of experiments \\
\hline
\end{tabular}

Table 3.1: Table summarizing the sources of experimental data used to calibrated the Grade 91 inelastic model

In the Kocks-Mecking equation relative temperatures must be converted to Kelvin absolute temperatures.

The Kocks-Mecking model rate sensitivity parameters fall into the second category. As described in the previous chapter, these properties can be determined from a bilinear fit to experimental data plotted on a Kocks-Mecking diagram. Figure 2.1 is a Kocks-Mecking diagram for Grade 91 plotting data from the tension, creep, and stress relaxation tests summarized in Table y. The Kocks-Mecking model parameters $A, B, C$, and $g_{0}$ were established by fitting a bilienar model to this data using nonlinear least-squares regression. In addition to these parameters, defining the normalized activation energy $g$ requires several physical constants and the reference strain rate $\dot{\varepsilon}_{0}$. This reference strain rate was established by hyperparameter optimization. Potential reference strain rates were considered in the range from $10^{0} \mathrm{~s}^{-1}$ to $10^{10} \mathrm{~s}^{-1}$ and the final model uses the value that gives the smallest standard error when comparing the experimental data to the best bilinear fit.

Table 3.3 lists the physical constants and the optimal value of the reference strain rate. Table 3.4 lists the best-fit Kocks-Mecking parameters for Grade 91

The rest of the parameters were calibrated using genetic algorithm (GA) optimization. Based on a simple hyperparameter optimization study we use two backstresses in the final model. We elected to control the values of these parameters at six interpolation control points at $25,400,500,550,600$, and $650^{\circ} \mathrm{C}$. In between these temperatures the model linearly interpolates the parameter values. Each temperature requires defining 15 parameters, for a total of 90 parameters to calibrate.

The fitness metric used in the GA is the integrated difference between some response curve describing the experimental data and a corresponding simulation. For example, for a tension test the metric for a single test is

$$
e_{i}=\int_{0}^{\varepsilon_{\max }}\left|\sigma_{e x p}(\varepsilon)-\sigma_{\text {model }}(\varepsilon)\right| d \varepsilon
$$

where $\sigma_{\text {exp }}(\varepsilon)$ is the experimental stress-strain curve measured in the experiment and $\sigma_{\text {model }}(\varepsilon)$ is the stress-strain curve predicted by a simulation using the inelastic material model at the 
Development of Grade 91 inelastic model for incorporation in ASME Division 5

July 2018

\begin{tabular}{|c|c|c|c|}
\hline $\begin{array}{l}\text { Temperature } \\
\left({ }^{\circ} \mathrm{C}\right)\end{array}$ & $\begin{array}{l}\text { Young's Modulus } \\
(\mathrm{MPa})\end{array}$ & Poisson's ratio & $\begin{array}{l}\text { Coefficient of thermal expansion } \\
\left(10^{-6 \frac{m m}{m m}} /{ }^{\circ} \mathrm{C}\right)\end{array}$ \\
\hline 20 & 213000 & 0.3 & 10.5 \\
\hline 50 & - & 0.3 & 10.8 \\
\hline 75 & - & 0.3 & 11.0 \\
\hline 100 & 208 & 0.3 & 11.2 \\
\hline 125 & - & 0.3 & 11.4 \\
\hline 150 & 205 & 0.3 & 11.6 \\
\hline 175 & - & 0.3 & 11.8 \\
\hline 200 & 201 & 0,3 & 12.0 \\
\hline 225 & - & 0.3 & 12.2 \\
\hline 250 & 198 & 0.3 & 12.4 \\
\hline 275 & - & 0.3 & 12.5 \\
\hline 300 & 195 & 0.3 & 12.7 \\
\hline 325 & - & 0.3 & 12.8 \\
\hline 350 & 191 & 0.3 & 13.0 \\
\hline 375 & - & 0.3 & 13.1 \\
\hline 400 & 187 & 0.3 & 13.3 \\
\hline 425 & - & 0.3 & 13.4 \\
\hline 450 & 183 & 0.3 & 13.6 \\
\hline 475 & - & 0.3 & 13.7 \\
\hline 500 & 179 & 0.3 & 13.8 \\
\hline 525 & - & 0.3 & 14.0 \\
\hline 550 & 174 & 0.3 & 14.2 \\
\hline 575 & - & 0.3 & 14.4 \\
\hline 600 & 168 & 0.3 & 14.6 \\
\hline 625 & - & 0.3 & 14.9 \\
\hline 650 & 161 & 0.3 & 15.2 \\
\hline
\end{tabular}

Table 3.2: Table of elastic and thermal properties for the Grade 91 model. These properties are taken directly from Section III, Division 5 of the ASME Code [1].

\begin{tabular}{lll}
\hline Constant & Description & Value \\
\hline$\dot{\varepsilon}_{0}$ & Reference strain rate & $10^{10} \mathrm{~s}^{-1}$ \\
$k$ & Boltzmann constant & $1.38064 \times 10^{-20} \frac{\mathrm{mJ}}{{ }^{\circ} \mathrm{C}}$ \\
$b$ & Burgers vector length & $2.48 \times 10^{-7} \mathrm{~mm}$ \\
\hline
\end{tabular}

Table 3.3: Physical constants used in the Kocks-Mecking model.

\begin{tabular}{lc}
\hline Parameter & Value \\
\hline$A$ & -9.698 \\
$B$ & -8.509 \\
$C$ & -5.119 \\
$g_{0}$ & 0.3496 \\
\hline
\end{tabular}

Table 3.4: Calibrated material properties for the Kocks-Mecking rate sensitivity model 


\begin{tabular}{ll}
\hline Parameter & Value \\
\hline Population size & 75 \\
Elitism & 5 \\
Tournament size & 3 \\
Cross over probability & 0.5 \\
Mutation probability & 0.2 \\
Individual parameter mutation probability & 0.05 \\
$\eta$ polynomial mutation parameter & 2.0 \\
\hline
\end{tabular}

Table 3.5: Hyperparameters used in the genetic algorithm optimization scheme.

experimental temperature and strain rate. Similar comparison metrics can be defined for each of test types used to calibrate the model. For the cyclic tests the metrics are defined using per-cycle quantities of maximum, mean, or minimum stress or strain, depending on the test type, to avoid integrating through the entire stress-strain history.

The overall fitness function is the weighted sum of each individual comparison metric between an experiment and a corresponding simulation. The weights for each test were selected to normalize the data to account for the different number of types of tests in each category. That is, if there are $m$ tests of a certain type (e.g. creep tests) then the calibration weight is $1 / m$.

The genetic algorithm works with a "population" of "individual" models. Each individual is encoded with a genome - here the unrolled vector of the complete model parameters. The parameters describing each individual, i.e. fully describing the model, are initialized randomly, within some reasonable bounds. The GA used here has a population size of 75 . The genetic algorithm evolves this population to increase the overall mean population fitness, i.e. increase the average agreement between the models and the experimental data.

GAs are iterative. In each iteration, often called a generation, the algorithm applies a series of processes to the population that modifies the genome of each individual to improve the mean population fitness. These steps, for the specific GA used here, are:

1. Fitness evaluation: run a simulation for each experiment in the database and sum the weighted comparison metrics to assign a fitness to each individual in the population.

2. Selection: the model uses tournament selection with a tournament size of 3 to select pairs of individuals for the next step.

3. Reproduction: the selected pairs of individuals are used to produce a new, child individual through two point crossover.

4. Mutation: a bounded polynomial mutation is used to randomly alter some of the child parameters.

This process is used to create 70 new child individuals. The remaining five individuals the individuals in the parent population with the five best values of fitness. This selection strategy is called elitism. All these steps are more fully described in [14]. Table 3.5 lists the hyperparameters used in the GA optimization scheme. 


\begin{tabular}{llllllll}
\hline Parameter & Units & $25^{\circ} \mathrm{C}$ & $400^{\circ} \mathrm{C}$ & $500^{\circ} \mathrm{C}$ & $550^{\circ} \mathrm{C}$ & $600^{\circ} \mathrm{C}$ & $650^{\circ} \mathrm{C}$ \\
\hline$h$ & - & $2 \times 10^{-4}$ & $2 \times 10^{-4}$ & $2 \times 10^{-4}$ & $2 \times 10^{-4}$ & $2 \times 10^{-4}$ & $2 \times 10^{-4}$ \\
$l$ & - & 1.91 & 1.91 & 1.71 & 1.69 & 1.61 & 1.51 \\
$Q$ & $\mathrm{MPa}$ & -96 & -96 & -150 & -151 & -151 & -131 \\
$\delta$ & - & 2.00 & 1.71 & 1.71 & 1.51 & 1.51 & 1.00 \\
$C_{1}$ & $\mathrm{MPa}$ & 14500 & 15000 & 19000 & 19200 & 19900 & 19000 \\
$\gamma_{1}$ & - & 141 & 141 & 802 & 792 & 803 & 803 \\
$A_{1}$ & $\mathrm{MPa}^{1-\mathrm{a}_{1}}$ & $1 \times 10^{-15}$ & $1 \times 10^{-15}$ & $1 \times 10^{-15}$ & $1 \times 10^{-15}$ & $1 \times 10^{-15}$ & $1 \times 10^{-15}$ \\
$a_{1}$ & - & 3.5 & 3.5 & 5.97 & 5.97 & 7.47 & 9.46 \\
$C_{2}$ & $\mathrm{MPa}$ & 12500 & 12500 & 12500 & 12600 & 12400 & 12400 \\
$\gamma_{2}$ & - & 60.6 & 60.4 & 200 & 200 & 202 & 202 \\
$A_{2}$ & $\mathrm{MPa}^{1-\mathrm{a}_{2}}$ & $1 \times 10^{-15}$ & $1 \times 10^{-15}$ & $1 \times 10^{-15}$ & $1 \times 10^{-15}$ & $1 \times 10^{-15}$ & $1 \times 10^{-15}$ \\
$a_{2}$ & - & 3.5 & 3.5 & 5.96 & 5.96 & 7.51 & 9.53 \\
\hline
\end{tabular}

Table 3.6: Material properties calibrated with the GA optimization scheme

This process continues for 100 generations, which is a sufficient number of iterations to get to a stable population fitness. The final optimized model is the individual with the best fitness after 100 generations.

The evaluation of the population fitness scores can be done in parallel. In fact, each individual simulation of an experiment can be done independently of all the others. These evaluations were done in parallel on a cluster with 1600 cores. The complete optimization process requires over 1 week of wall time, representing about 300,000 core-hours of computational effort. The GA used here was implemented in Python using the DEAP framework [15].

This calibration process explicitly includes the temperature interpolation scheme in the fit because experimental data is available in the database for temperatures in between the model control points. The process does not fit parameters at several discrete temperatures with available experimental data and then assume that parameters can be interpolated between these fixed points. Instead, the interpolation process itself is part of the calibration - the GA aims to minimize the total error over all temperatures, not just at the temperature control points.

Table 3.6 lists the optimal parameter set calibrated with the GA. Tables 3.2, 3.3, and 3.4 , together with the mathematical definition of the model in the previous chapter, fully define the final model.

\subsection{Basic mechanical response of the model}

This section summarizes the basic mechanical response of the final model and compares the model predictions to the data used in the calibration process, described in the previous section. Figures 3.1-3.9 plot the model flow curves at fixed temperatures and different strain rates. The plots show the effect of the Kocks-Mecking model for rate sensitivity — at low temperatures the model is rate insensitive, the strain rate does not affect the flow curve. At high temperatures the model flow stress is rate-dependent. 
Development of Grade 91 inelastic model for incorporation in ASME Division 5

July 2018

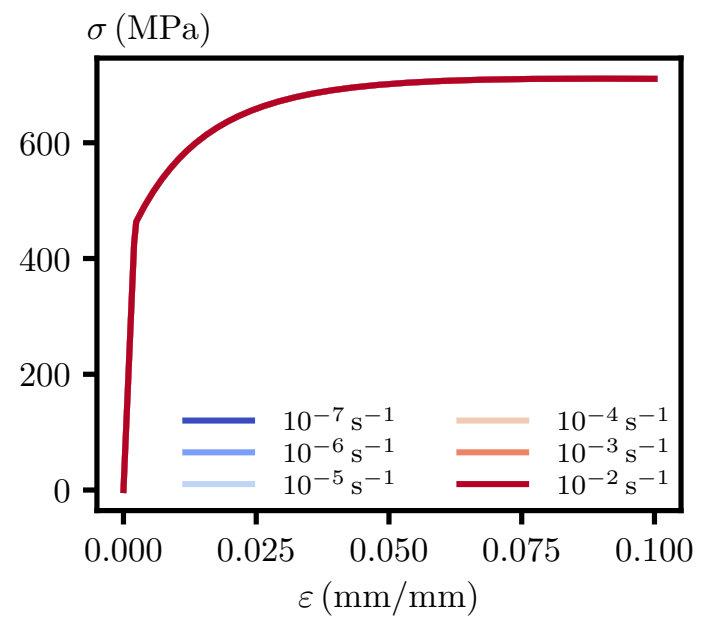

Figure 3.1: Model flow curves at $T=25^{\circ} \mathrm{C}$ as a function of increasing strain rate.

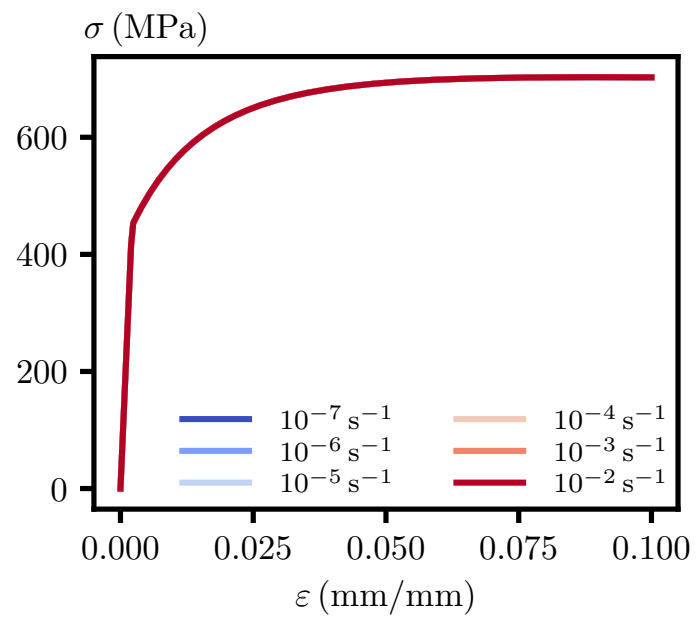

Figure 3.2: Model flow curves at $T=100^{\circ} \mathrm{C}$ as a function of increasing strain rate.

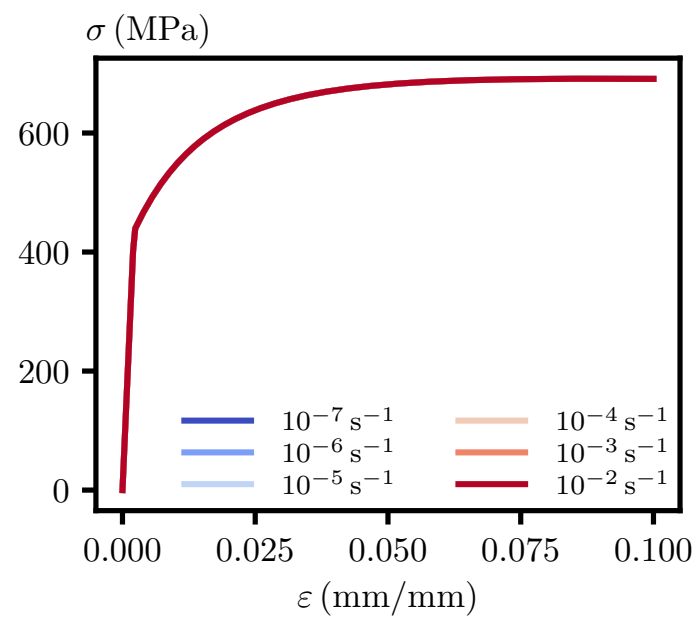

Figure 3.3: Model flow curves at $T=200^{\circ} \mathrm{C}$ as a function of increasing strain rate. 
Development of Grade 91 inelastic model for incorporation in ASME Division 5

July 2018

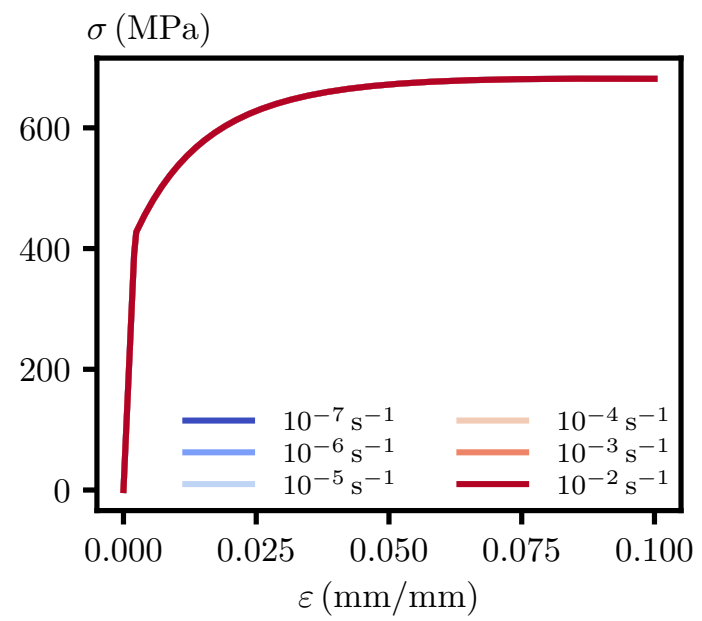

Figure 3.4: Model flow curves at $T=300^{\circ} \mathrm{C}$ as a function of increasing strain rate.

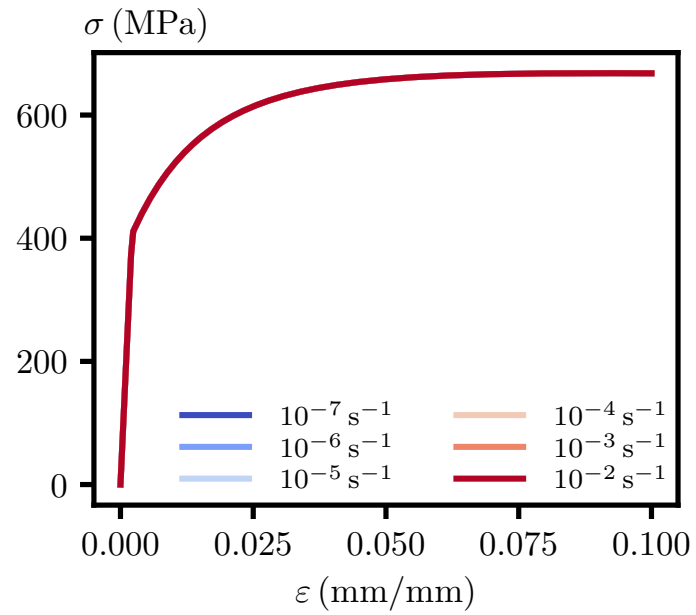

Figure 3.5: Model flow curves at $T=400^{\circ} \mathrm{C}$ as a function of increasing strain rate.

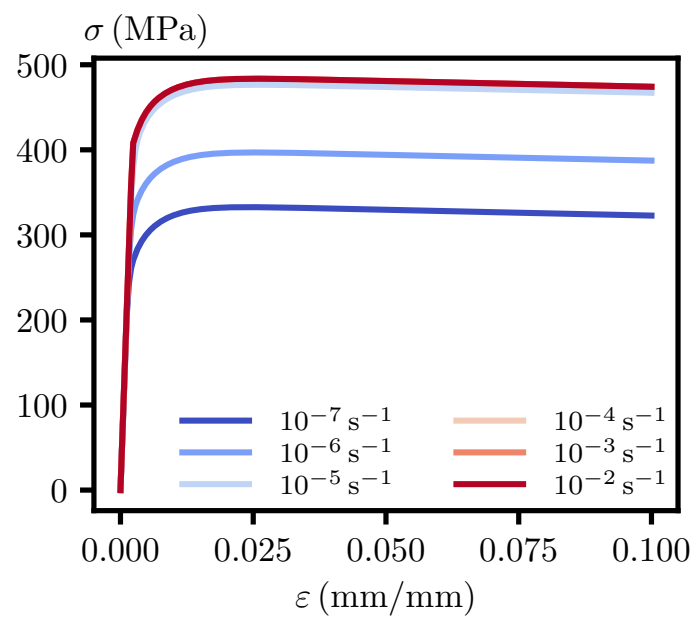

Figure 3.6: Model flow curves at $T=500^{\circ} \mathrm{C}$ as a function of increasing strain rate. 
Development of Grade 91 inelastic model for incorporation in ASME Division 5

July 2018

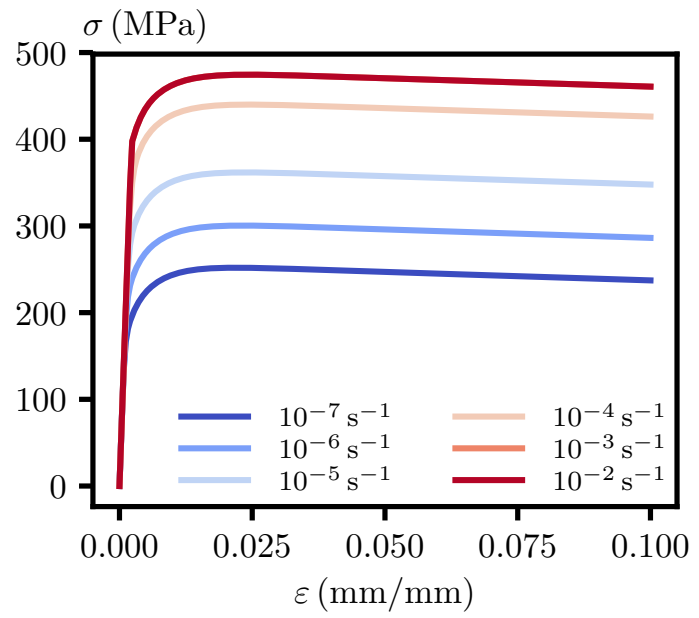

Figure 3.7: Model flow curves at $T=550^{\circ} \mathrm{C}$ as a function of increasing strain rate.

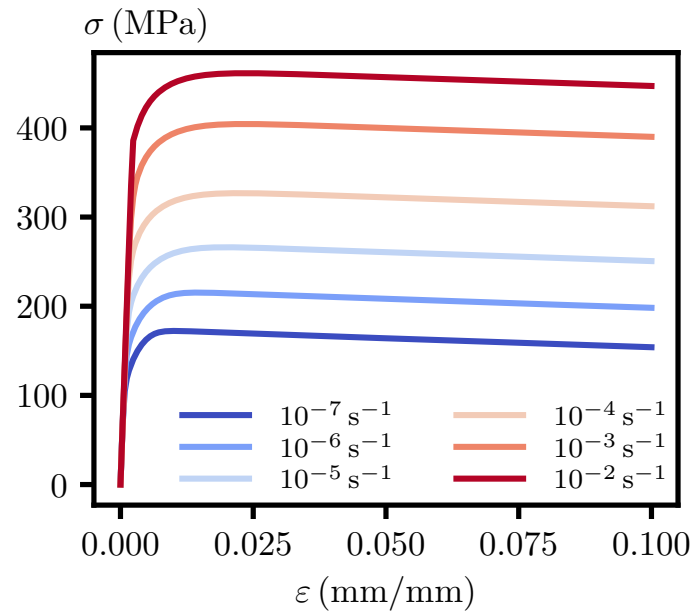

Figure 3.8: Model flow curves at $T=600^{\circ} \mathrm{C}$ as a function of increasing strain rate.

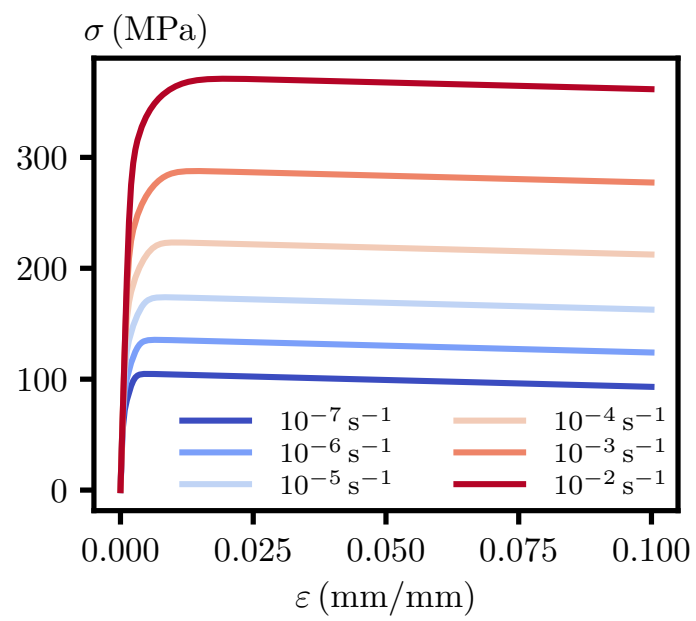

Figure 3.9: Model flow curves at $T=650^{\circ} \mathrm{C}$ as a function of increasing strain rate. 


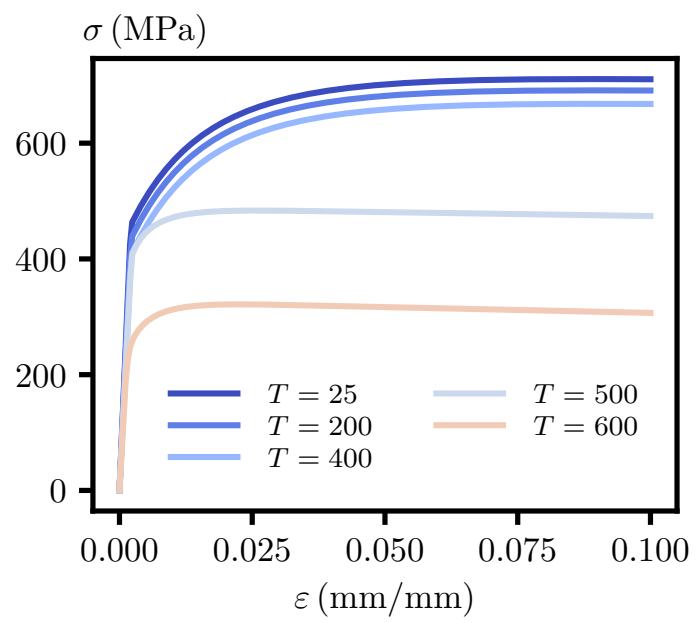

Figure 3.10: Model flow curves as a function of increasing temperature $\left(\right.$ in $\left.{ }^{\circ} \mathrm{C}\right)$ at fixed strain rate.

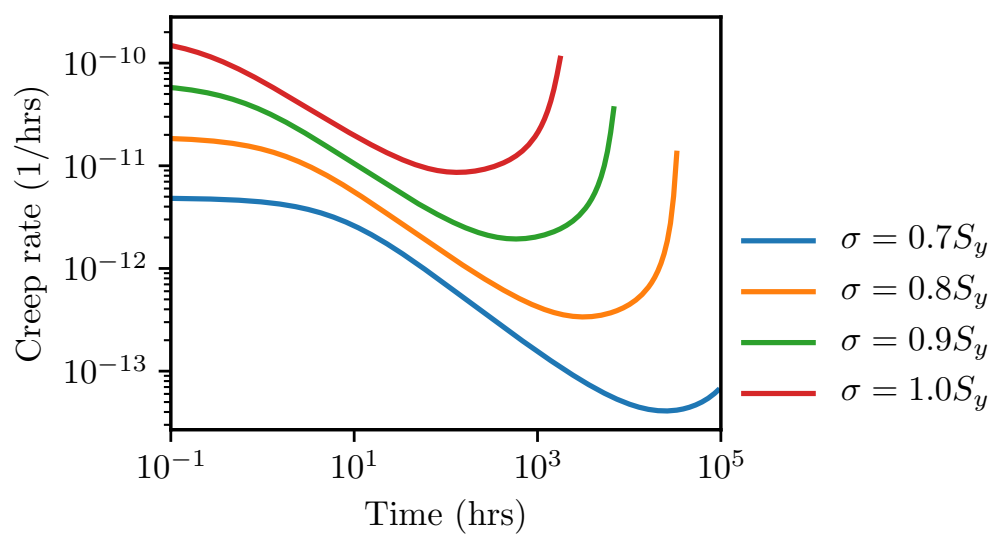

Figure 3.11: Model creep rate curves for $500^{\circ} \mathrm{C}$.

Figure 3.10 plots the model flow curves at fixed rate but increasing temperature. The model predicts a reasonable evolution of yield stress and work hardening/softening behavior with increasing temperatures. The yield stress decreases and the model switches from work hardening to work softening as the test temperature increases.

Figures 3.11-3.14 show simulated creep test results at several temperatures and a variety of applied stresses. The creep response of the model is reasonable for Grade 91. The creep curves transition from primary to tertiary creep without a long period of steady-state secondary creep. The static recovery terms adequately capture the increase in creep rate in the tertiary regime.

Finally, Figures 3.15-3.35 compare the model predictions to the experimental database used to calibrate the parameters. These curves cover a temperature range from 25 to $650^{\circ}$ C. Depending on the test temperature there are up to four plots per temperature showing results from uniaxial tension, creep, stress relaxation, and strain controlled cyclic tests. The model adequately captures the underlying fit data. However, this is not a true validation 


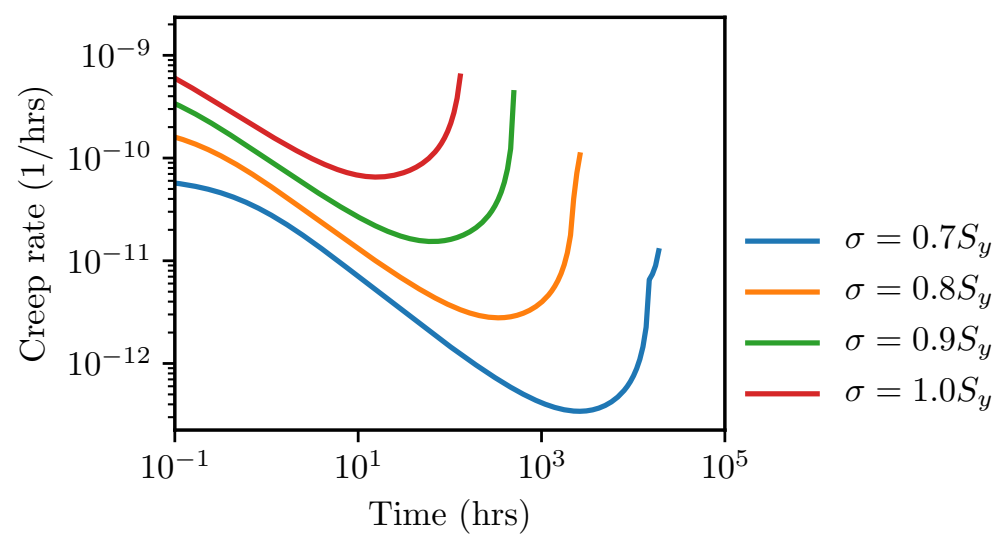

Figure 3.12: Model creep rate curves for $550^{\circ} \mathrm{C}$.

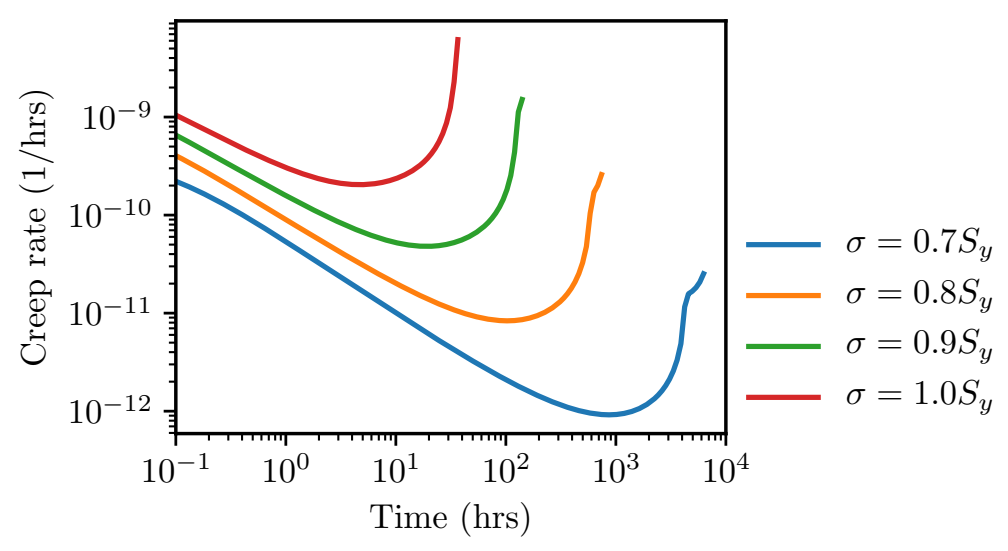

Figure 3.13: Model creep rate curves for $600^{\circ} \mathrm{C}$.

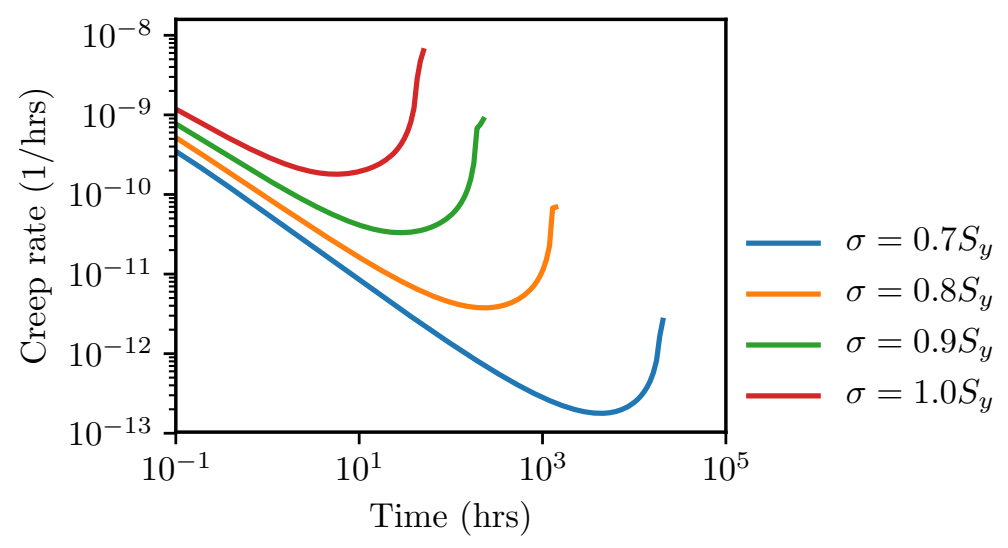

Figure 3.14: Model creep rate curves for $650^{\circ} \mathrm{C}$. 
Development of Grade 91 inelastic model for incorporation in ASME Division 5

July 2018

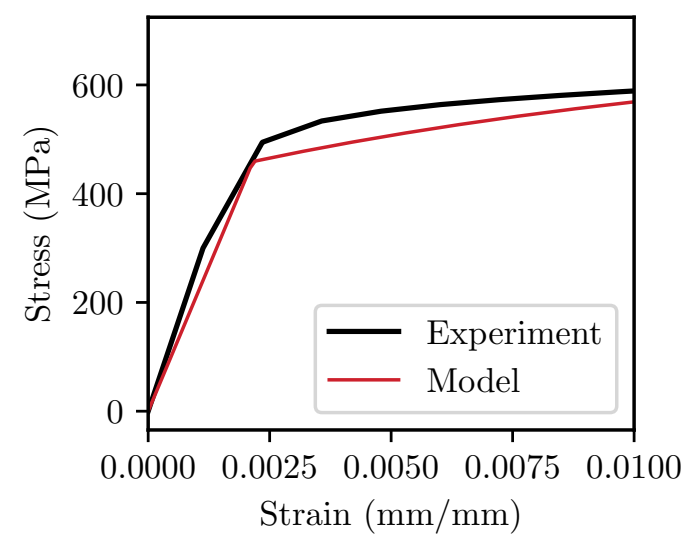

Figure 3.15: Comparison between model and experiment for uniaxial tension tests at $T=$ $25^{\circ} \mathrm{C}$.

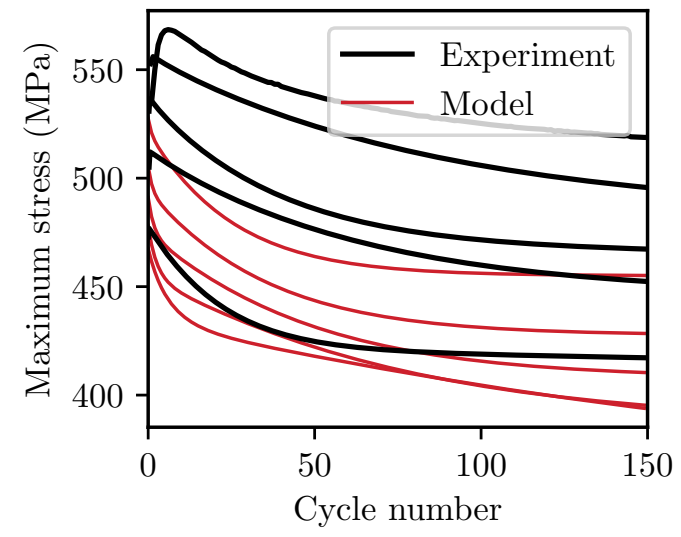

Figure 3.16: Comparison between model and experiment for strain controlled cyclic tests at $T=25^{\circ} \mathrm{C}$.

test, as this data was used to calibrate the model parameters. 
Development of Grade 91 inelastic model for incorporation in ASME Division 5

July 2018

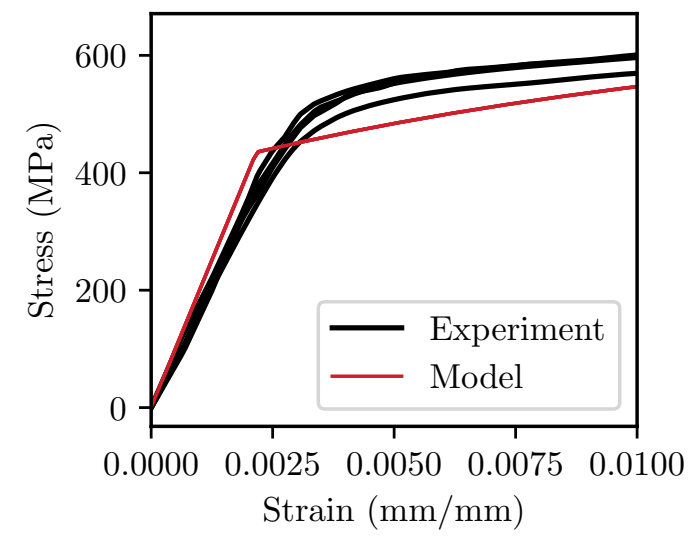

Figure 3.17: Comparison between model and experiment for uniaxial tension tests at $T=$ $200^{\circ} \mathrm{C}$.

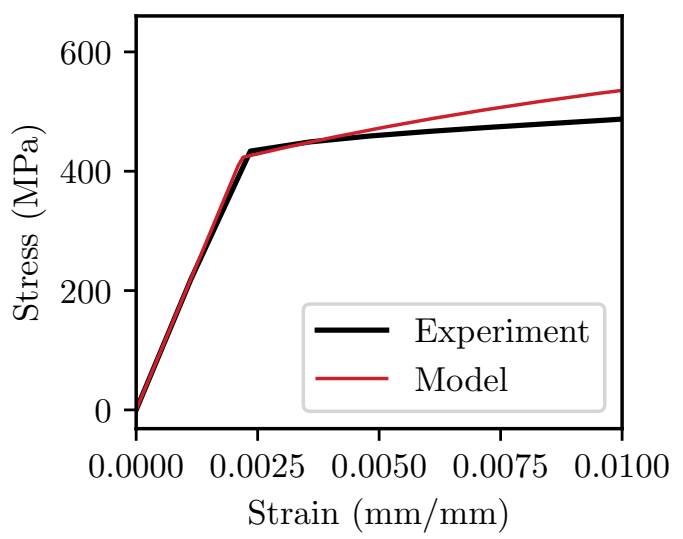

Figure 3.18: Comparison between model and experiment for uniaxial tension tests at $T=$ $300^{\circ} \mathrm{C}$. 
Development of Grade 91 inelastic model for incorporation in ASME Division 5

July 2018

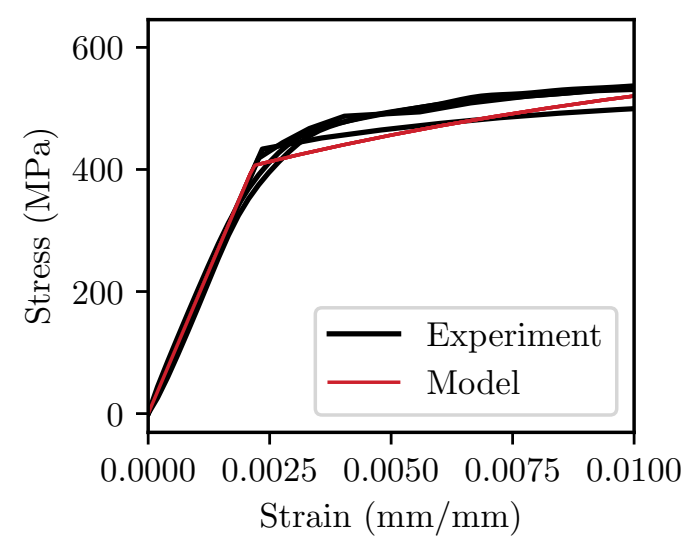

Figure 3.19: Comparison between model and experiment for uniaxial tension tests at $T=$ $400^{\circ} \mathrm{C}$.

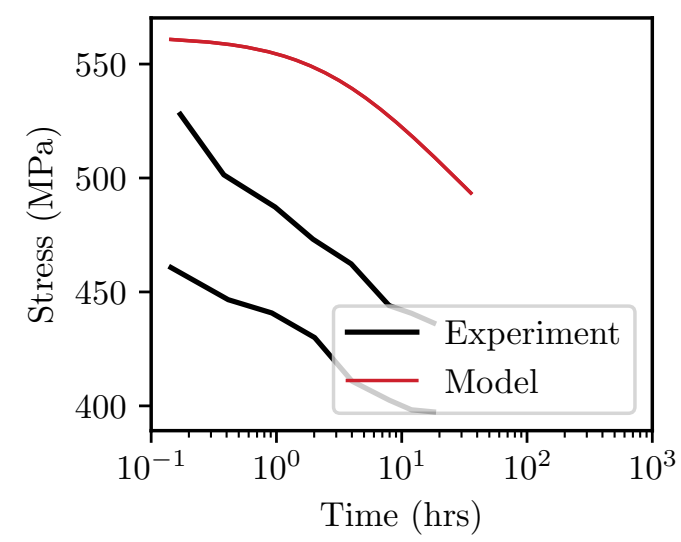

Figure 3.20: Comparison between model and experiment for stress relaxation tests at $T=$ $400^{\circ} \mathrm{C}$. 


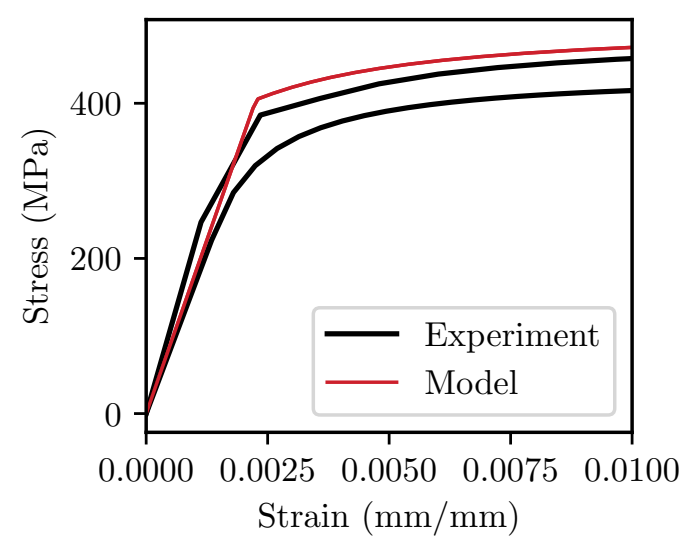

Figure 3.21: Comparison between model and experiment for uniaxial tension tests at $T=$ $500^{\circ} \mathrm{C}$.

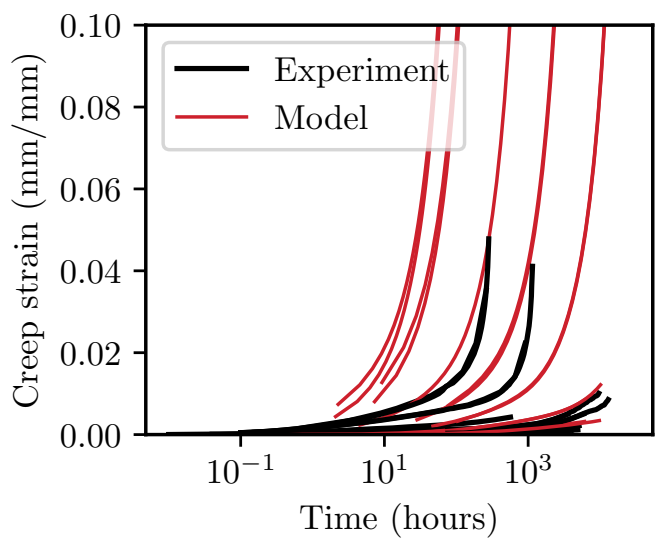

Figure 3.22: Comparison between model and experiment for creep tests at $T=500^{\circ} \mathrm{C}$.

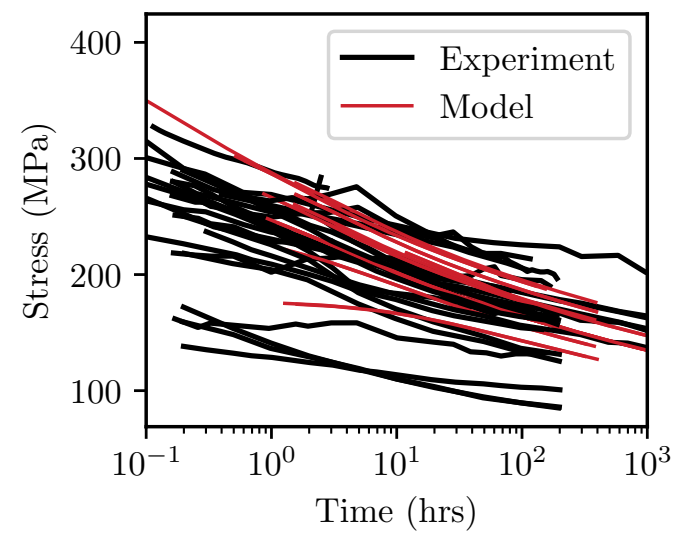

Figure 3.23: Comparison between model and experiment for stress relaxation tests at $T=$ $500^{\circ} \mathrm{C}$. 


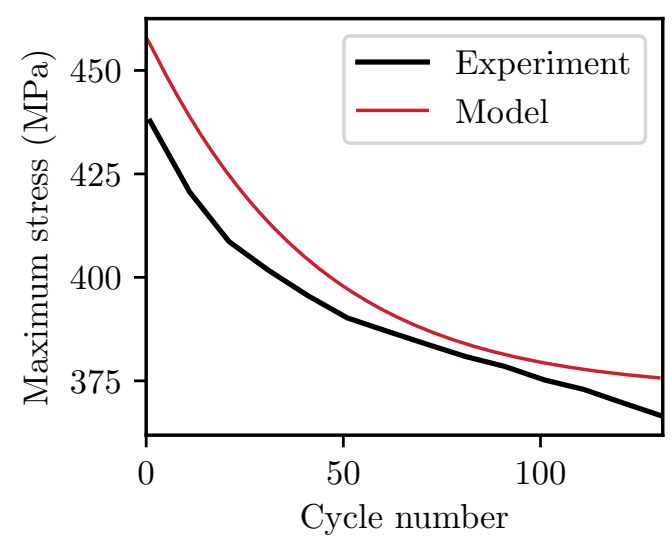

Figure 3.24: Comparison between model and experiment for strain controlled cyclic tests at $T=500^{\circ} \mathrm{C}$.

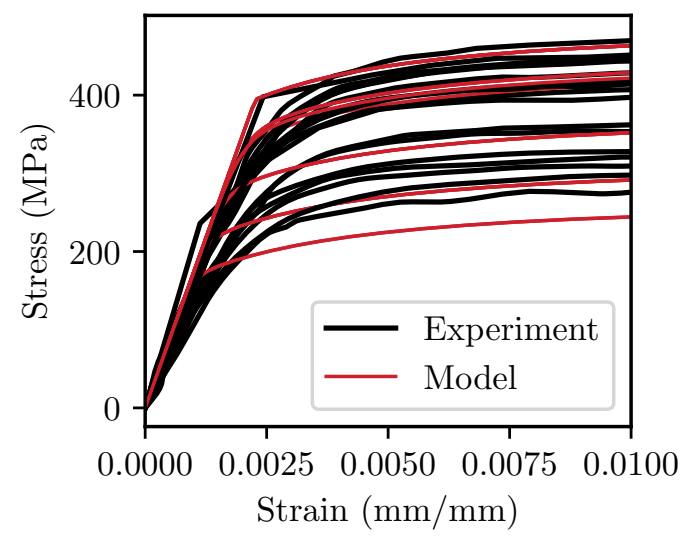

Figure 3.25: Comparison between model and experiment for uniaxial tension tests at $T=$ $550^{\circ} \mathrm{C}$.

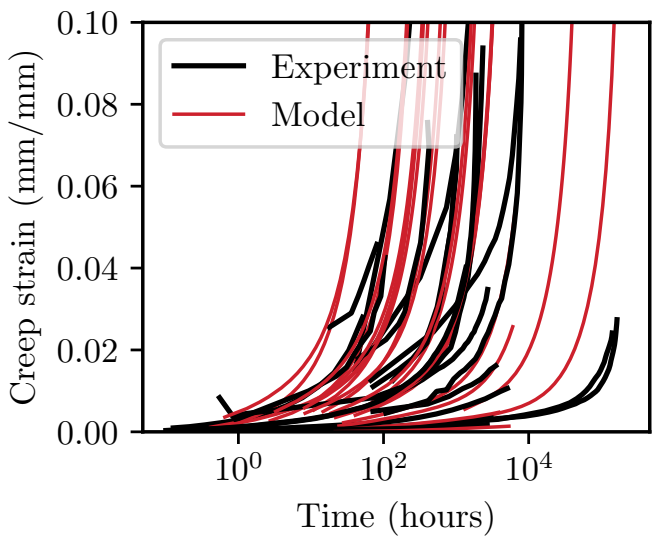

Figure 3.26: Comparison between model and experiment for creep tests at $T=550^{\circ} \mathrm{C}$. 


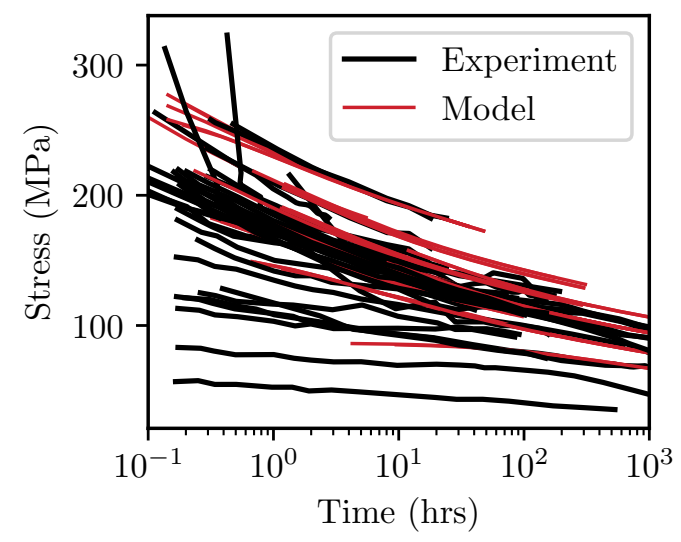

Figure 3.27: Comparison between model and experiment for stress relaxation tests at $T=$ $550^{\circ} \mathrm{C}$.

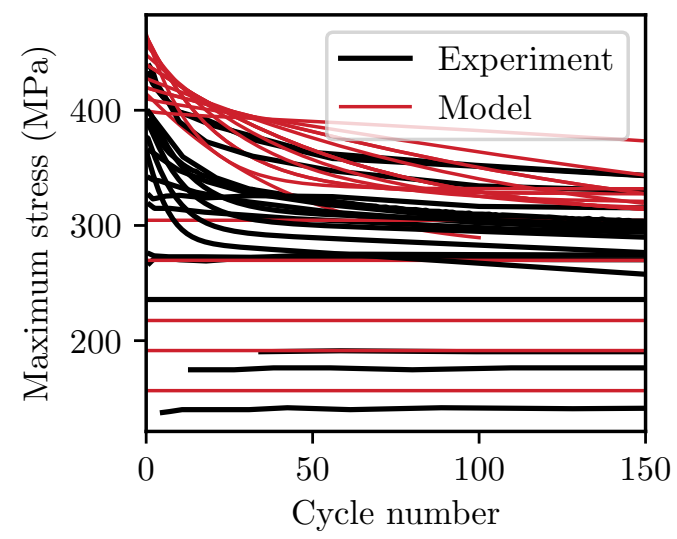

Figure 3.28: Comparison between model and experiment for strain controlled cyclic tests at $T=550^{\circ} \mathrm{C}$.

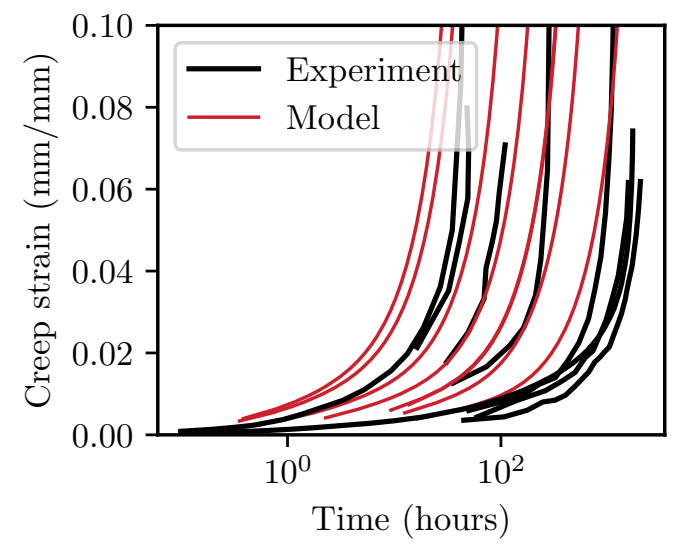

Figure 3.29: Comparison between model and experiment for creep tests at $T=575^{\circ} \mathrm{C}$. 


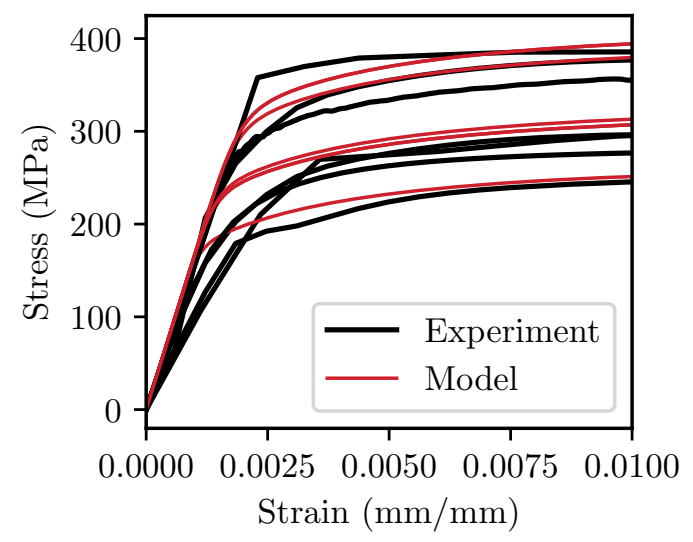

Figure 3.30: Comparison between model and experiment for uniaxial tension tests at $T=$ $600^{\circ} \mathrm{C}$.

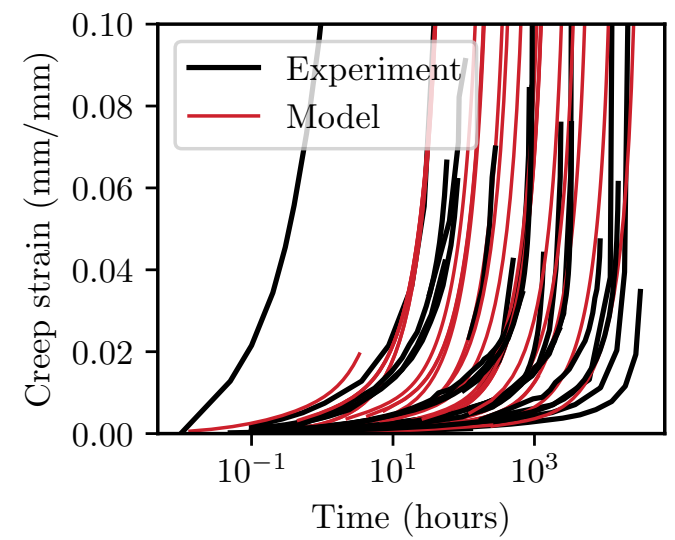

Figure 3.31: Comparison between model and experiment for creep tests at $T=600^{\circ} \mathrm{C}$.

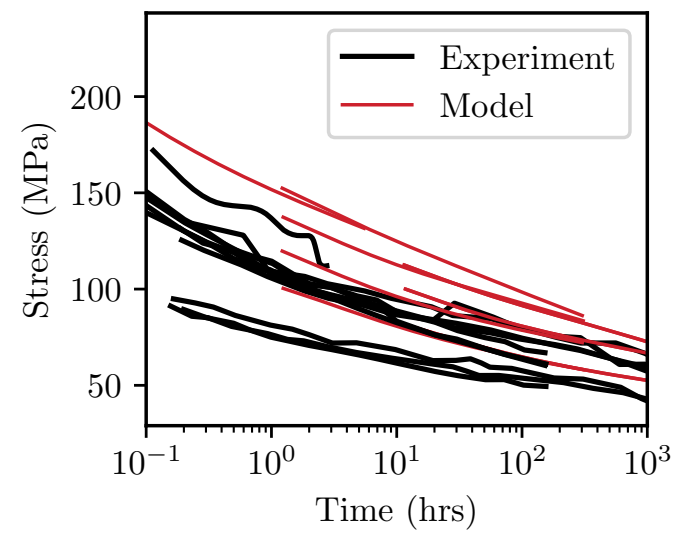

Figure 3.32: Comparison between model and experiment for stress relaxation tests at $T=$ $600^{\circ} \mathrm{C}$. 
Development of Grade 91 inelastic model for incorporation in ASME Division 5

July 2018

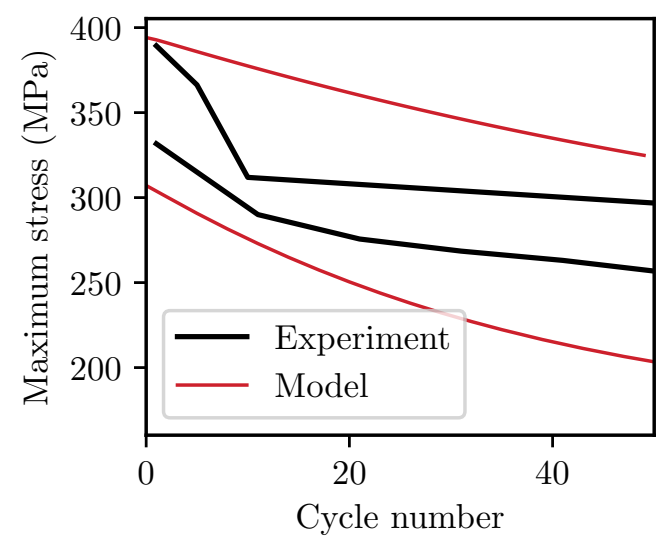

Figure 3.33: Comparison between model and experiment for strain controlled cyclic tests at $T=600^{\circ} \mathrm{C}$.

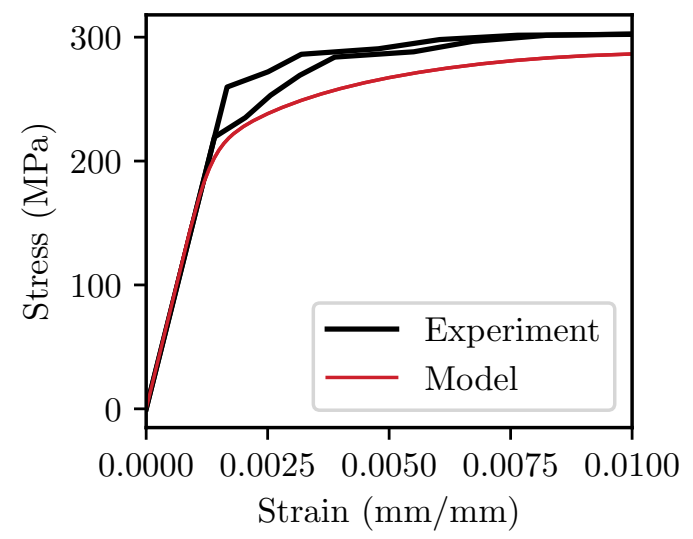

Figure 3.34: Comparison between model and experiment for uniaxial tension tests at $T=$ $650^{\circ} \mathrm{C}$.

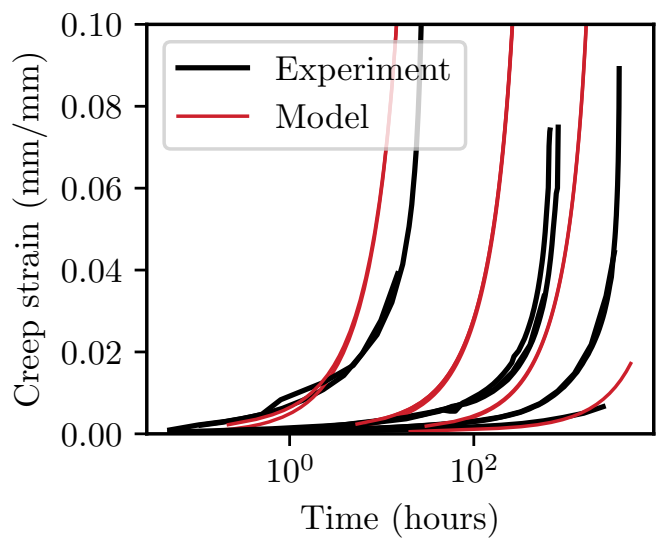

Figure 3.35: Comparison between model and experiment for creep tests at $T=650^{\circ} \mathrm{C}$. 


\section{Model validation}

This chapter validates the model through comparison to experimental data. The validation data used here was, in general, not used to fit the model parameters. This ensure the validation data did not bias the model fit. This chapter is structured to address the key model features identified in the introduction.

\subsection{Batch and product form variation}

Figure 4.1 plots the yield stress as a function of temperature predicted by the model at the fixed, ASTM E-21 [4] strain rate of $\dot{\varepsilon}=8.33 \times 10^{-5} \mathrm{~s}^{-1}$. Also shown on the figure are the data used by ASME to determine the Code value of yield stress $S_{y}$. This figure serves two purposes. Most of the ASME data was not used to fit the model so this figure validates the model yield stress as a function of temperature. There is likely some overlap between the model fit database and the ASME database that cannot be eliminated, as the ASME metadata is insufficient to determine which tests overlap. However, the ASME database contains far more yield stress tests than the full uniaxial flow stress tests used in fitting the model, so the two sets of data are mostly independent. The model captures the mean behavior of the ASME dataset, implying the model is a good description of the average material response of Grade 91.

The second purpose of the figure is to illustrate the large material heat and product form variation in the material properties of Grade 91. The calibrated model is deterministic and does not capture this scatter. The Section III, Division 5 approach for design by inelastic analysis uses an average property structural analysis and bounds variation in the design allowables. So, for Code use, an inelastic model capturing the average material response is adequate.

However, this scatter in actual material properties means that the average inelastic model will never exactly match the experimental response measured for any particular sample of Grade 91 material. Consider the simplest case where we use the model to predict a measured experimental value of yield stress. Figure 4.1 implies that, due to batch and product form variation, it is extremely improbable that the model prediction will match the experimental measurement. This is acceptable for design using the ASME Code. However, it does make validating the model challenging as we cannot expect perfect agreement between the model and the validation tests.

Therefore, the expectation when comparing the model the validation tests is that the model response is "reasonable." The model should capture the correct trend in the experimental data but we must allow significant differences in the model flow stress, compared to the flow stress measured in the experiment.

\subsection{Temperature variation}

The model must correctly capture the average response of Grade 91 over the ASME allowable use temperature range. Thermomechanical tests assess the ability of the model to capture the mechanical response of the material over a temperature-varying load history. These types of tests are particularly relevant for the design of high temperature reactors, where thermal transients will be significant in design load cases. 


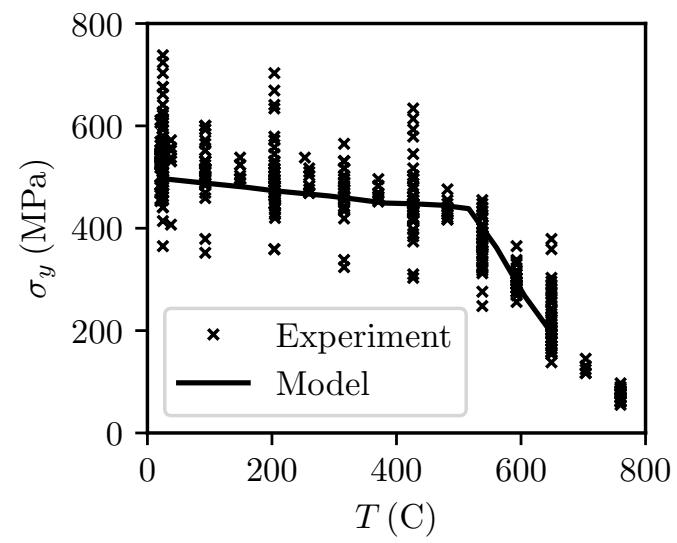

Figure 4.1: Model prediction for the material yield stress as a function of temperature (solid line) plotted with the data underlying the ASME Code values of yield stress $S_{y}$ (points).

Figures 4.2 and 4.3 compare the model predictions to two thermomechanical tests performed by Oak Ridge National Laboratory [34]. These tests were done with fully-constrained uniaxial samples. Temperature variation provides all the mechanical load through constrained thermal expansion. One test cycled the temperature of the sample between $500^{\circ} \mathrm{C}$ and $600^{\circ} \mathrm{C}$ and the other test cycles between $150^{\circ} \mathrm{C}$ and $650^{\circ} \mathrm{C}$. For each figure subfigure (a) shows the specimen temperature history and subfigure (b) compares the model prediction (black) to the experimental results (red) by plotting the stress in the sample as a function of time. The figures show good qualitative agreement between the model and simulation. The direction of thermal ratcheting is consistent as is the trend in the evolution of the cyclic thermal stress.

These thermomechanical tests are challenging to accurately model as the response of the test depends on the temperature-dependent material properties over a wide range of temperatures. The success of the model in matching the available experimental data implies the Grade 91 inelastic model captures the average response of the material undergoing representative thermal loads.

\subsection{Long term creep}

Representing the long-term creep response of Grade 91 is critical for a model used to design reactor structure for long service lives. The previous chapter shows that the model accurately recover the creep test data used to calibrate the model parameters.

To validate the model's creep response Figs. 4.4-4.7 compare simulated isochronous curves to the isochronous curves for Grade 91 in Section III, Division 5 of the ASME Code. The Code curves are supposed to represent the average creep response of Grade 91 and are constructed using a wide range of available creep test data. The simulated curves and the ASME curves are very similar in the operating creep temperature range of $500^{\circ}$ to $650^{\circ}$ $\mathrm{C}$, demonstrating that the model accurately represents the average response of Grade 91 material. 


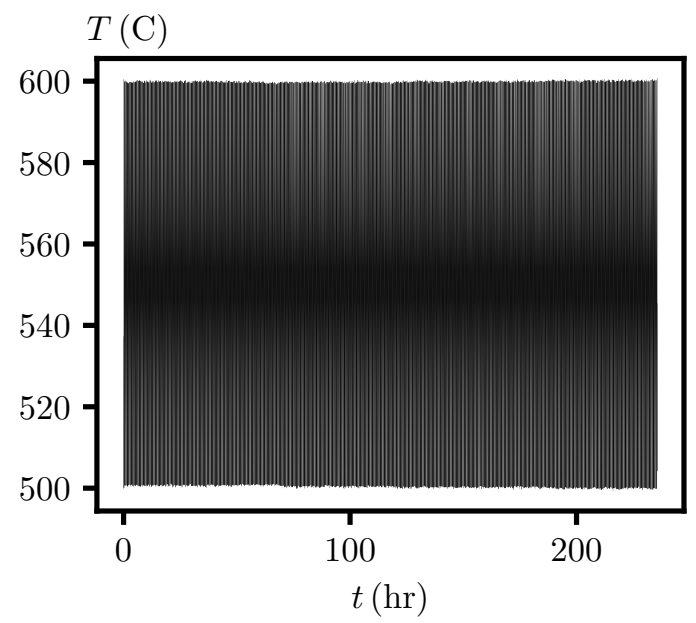

(a) Test temperature history.

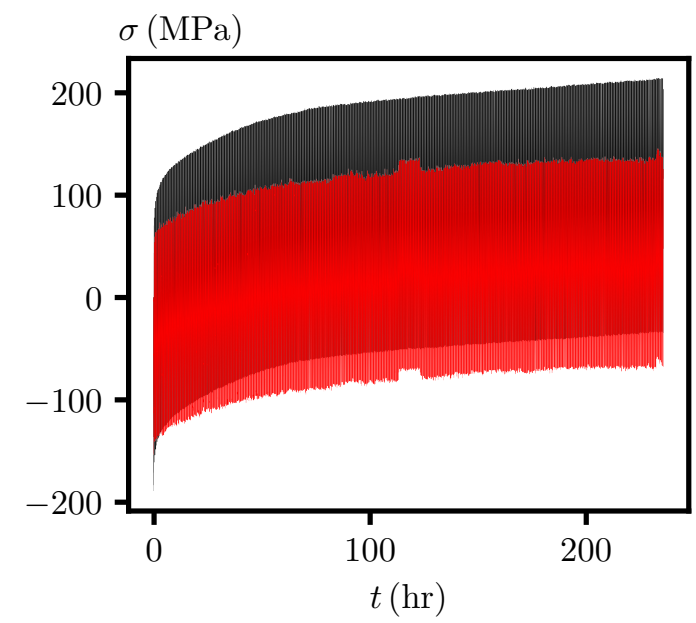

(b) Simulation results compared to the test data plotted as a stress versus time history. The black line is the simulation and the red line is the experimental data

Figure 4.2: Comparison between the results of a thermomechanical test on a Grade 91 sample and corresponding simulation predictions.

\subsection{Creep-fatigue loading}

As described in the introduction, capturing the response of Grade 91 under cyclic, creepfatigue loading is crucial in accurately determining the design life of structural components. The Code uses both the strain range and the stress relaxation profile from a component analysis in computing the creep-fatigue life of a structure. Figure 4.8 shows several different representations of a comparison between a simulation and a creep-fatigue experiment conducted at Argonne National Laboratory. The test and simulation cycle the material under fully reversed strain controlled loading with a strain range of $\Delta \varepsilon=0.5 \%$, a strain rate of $\dot{\varepsilon}=10^{-3} \mathrm{~s}^{-1}$, and at a temperature of $T=550^{\circ} \mathrm{C}$. The test holds the specimen at the maximum tensile strain for $t=100 \mathrm{~min}$ each cycle.

Subfigure (a) compares the model (black) and experimental (red) hysteresis loops over the full test. Subfigure (b) shows the loop during the second load cycle. Subfigure (c) shows the stress relaxation profile (stress versus time) during the tension hold in the second cycle. Subfigures (d) and (e) show the hysteresis loop and the stress relaxation profile during the 50th load cycle.

Given the scatter caused by batch variation, the model reasonably predicts both the stress range and the stress relaxation profile measured in the experiment. This validation test demonstrates that the inelastic model can be used to design structures for creep fatigue loading, following the ASME procedure. 


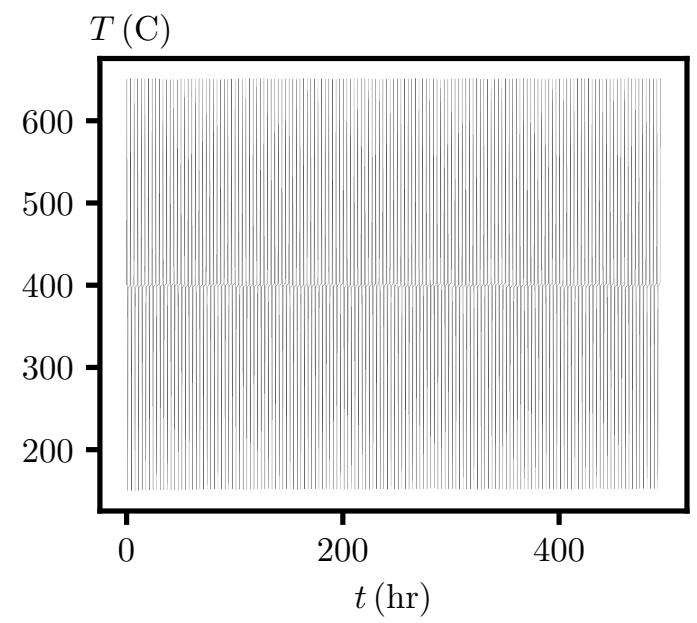

(a) Test temperature history.

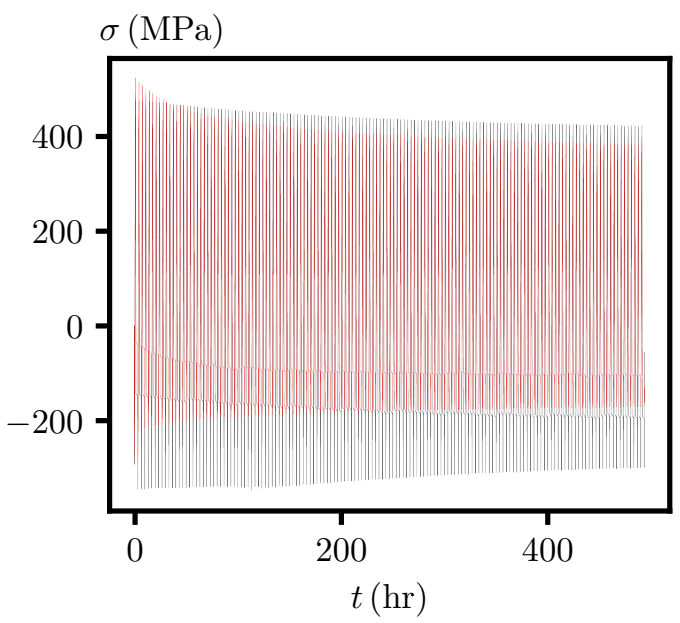

(b) Simulation results compared to the test data plotted as a stress versus time history. The black line is the simulation and the red line is the experimental data.

Figure 4.3: Comparison between the results of a thermomechanical test on a Grade 91 sample and corresponding simulation predictions.

\subsection{Anomalous ratcheting}

Finally, the introduction noted anomalous ratcheting in Grade 91, where the material ratchets in the tensile direction under fully-reversed stress controlled load. The non- $J_{2}$ flow rule used in the final model is designed to capture this behavior. Figure 4.9 compares experimental data to the model predictions for stress-controlled tests with various $R$ ratios. The model correctly predicts the ratcheting trend, including capturing the tendency of the material to ratchet under fully-reversed, stress-controlled loading $(R=-1)$.

These results show that the final inelastic model for Grade 91 captures all the key structural responses identified in the introduction as being important for ASME design. This model can therefore be proposed for incorporation into the ASME Code as part of a nonmandatory appendix describing reference viscoplastic models that can be used to execute the ASME design by inelastic analysis design provisions. 
Development of Grade 91 inelastic model for incorporation in ASME Division 5

July 2018

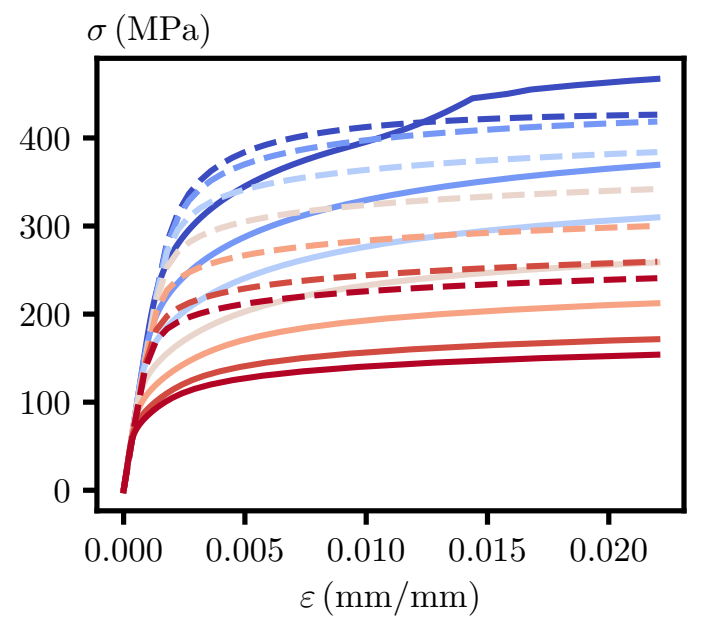

Figure 4.4: Comparison between model (solid) and Code (dashed) isochronous stress-strain curves at $500^{\circ} \mathrm{C}$. From top to bottom and blue to red colors the curves are for 1, 10, 100, $1,000,10,000,100,000$, and 300,000 hours.

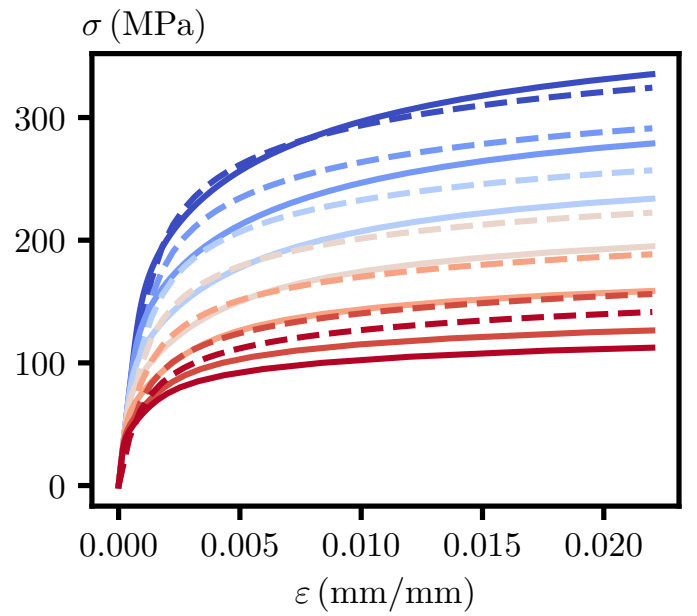

Figure 4.5: Comparison between model (solid) and Code (dashed) isochronous stress-strain curves at $550^{\circ} \mathrm{C}$. From top to bottom and blue to red colors the curves are for 1, 10, 100, 1,000, 10,000, 100,000, and 300,000 hours. 
Development of Grade 91 inelastic model for incorporation in ASME Division 5

July 2018

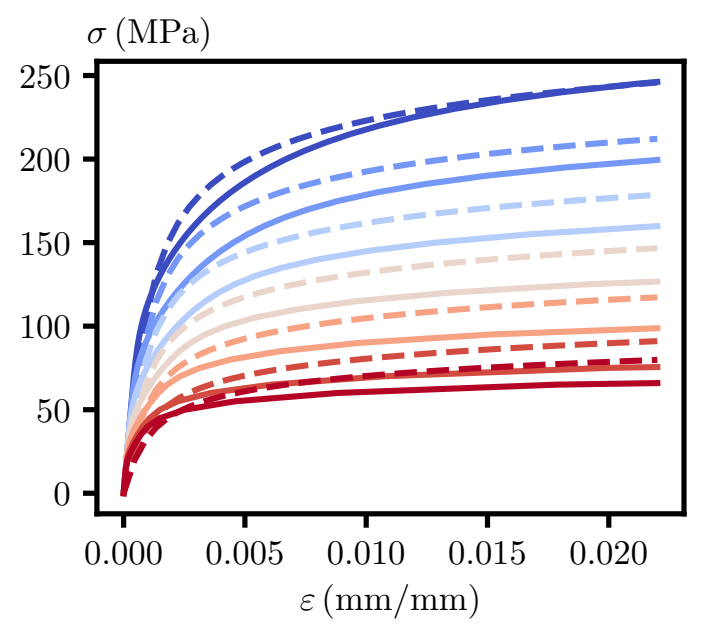

Figure 4.6: Comparison between model (solid) and Code (dashed) isochronous stress-strain curves at $600^{\circ} \mathrm{C}$. From top to bottom and blue to red colors the curves are for 1, 10, 100, 1,000, 10,000, 100,000, and 300,000 hours.

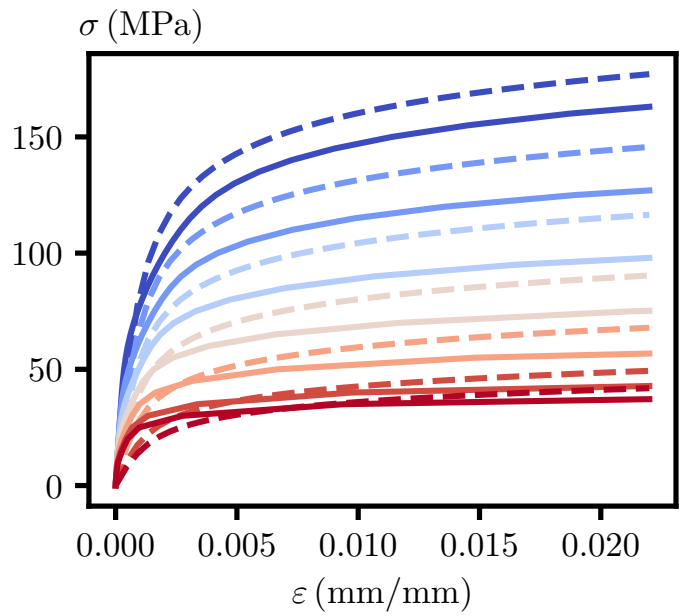

Figure 4.7: Comparison between model (solid) and Code (dashed) isochronous stress-strain curves at $650^{\circ} \mathrm{C}$. From top to bottom and blue to red colors the curves are for 1, 10, 100, 1,000, 10,000, 100,000, and 300,000 hours. 


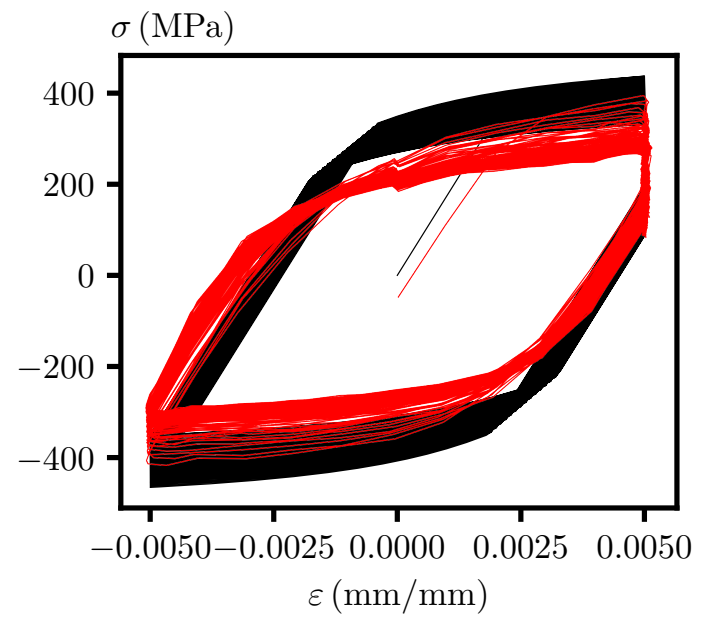

(a) Complete stress-strain hysteresis loops.

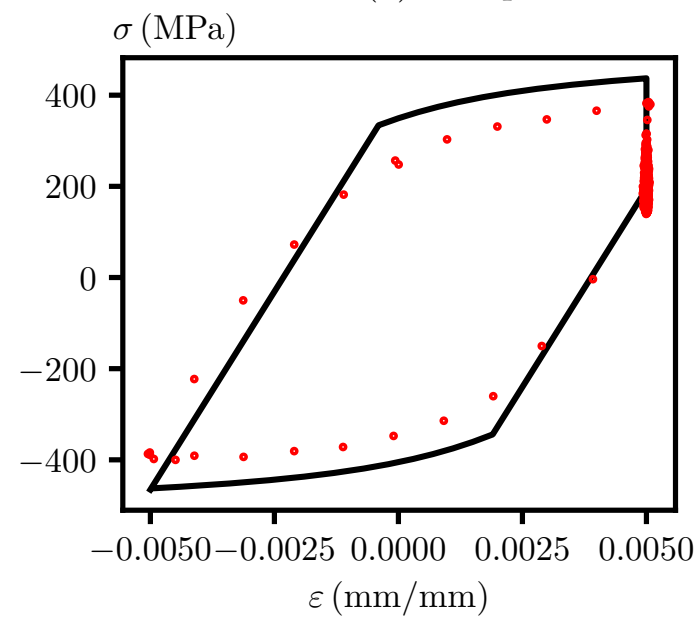

(b) Cycle 2 stress-strain hysteresis loop.

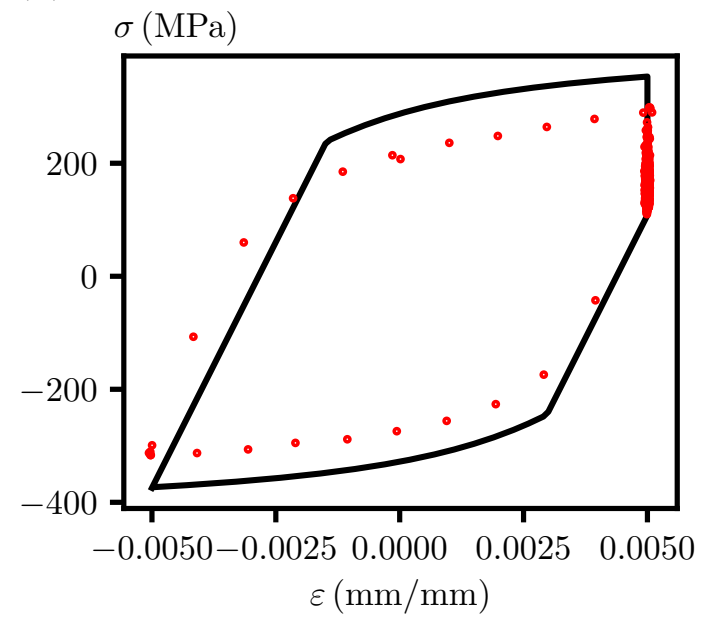

(d) Cycle 50 stress-strain hysteresis loop.

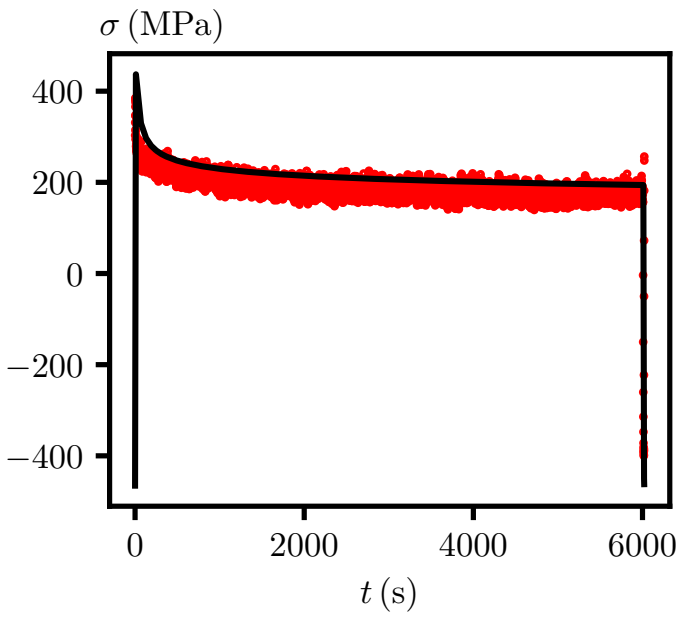

(c) Cycle 2 stress-strain hysteresis loop.

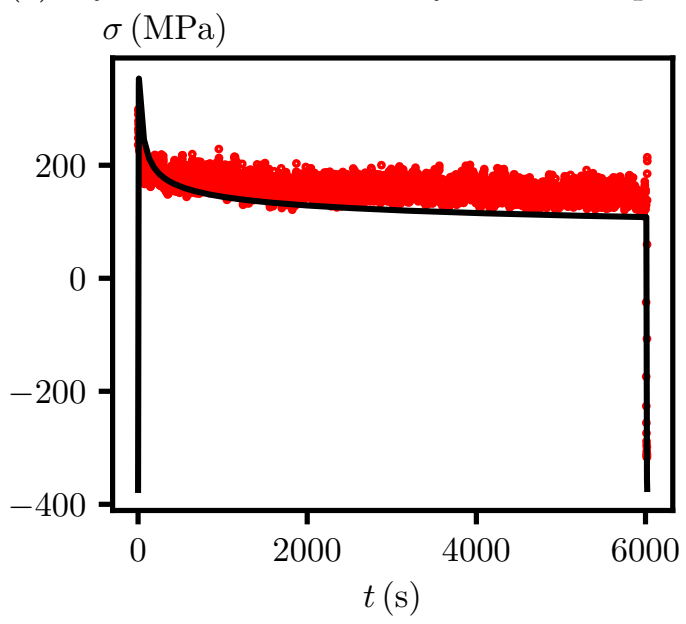

(e) Cycle 50 stress-strain hysteresis loop.

Figure 4.8: Comparison between model (black) and experiment (red) for a creep-fatigue test. 
Development of Grade 91 inelastic model for incorporation in ASME Division 5

July 2018

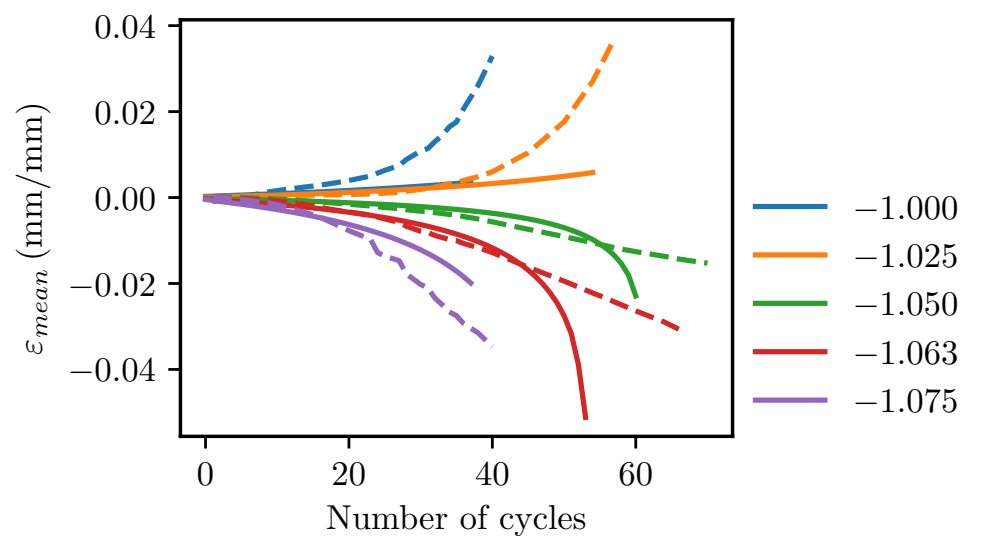

Figure 4.9: Comparison between model (solid) and experiment (dashed) for several stress controlled cyclic tests with various $R$ ratios. 


\section{Conclusions}

This report describes a material model for Grade 91 steel suitable for use with the Section III, Division 5 design by inelastic analysis provisions of the ASME Boiler and Pressure Vessel Code. The model captures the average response of Grade 91, accounting for batch and product formation variations, and represents several key deformation modes identified in this report as critical for design. The report validates the model against several specialized experimental tests.

The methods developed here, particularly the genetic algorithm optimization process, can be applied to the remaining Class A materials to develop a nonmandatory appendix describing reference material models suitable for Code design use. Critical deformation mechanism will vary for the different materials and so the model forms will also vary. However, the same general process can be used to calibrate the models, once a general model form is developed.

The Kocks-Mecking model rate sensitivity model can also be applied to the other materials. Though Grade 91 likely has the lowest rate-sensitivity temperature of all the Class A materials, the other materials will also transition from a rate independent to a rate dependent plastic response.

The model for Grade 91 described here is substantially complete. If component test data becomes available in the future it should be validated against those results. The validation tests used here represent key features of a structural response, but a complete component test would be even more useful in validating that the model can be used for high temperature design calculations. 



\section{Acknowledgments}

The research was sponsored by the U.S. Department of Energy (DOE), under Contract No. DE-AC02-06CH11357 with Argonne National Laboratory, managed and operated by UChicago Argonne LLC. Programmatic direction was provided by the Office of Advanced Reactor Technologies (ART) of the Office of Nuclear Energy (NE).

The authors gratefully acknowledge the support provided by Alice Caponiti, Director, Office of Advanced Reactor Technologies (ART), Sue Lesica, Federal Manager, ART Advanced Materials Program, and Robert Hill of ANL, National Technical Director, ART Fast Reactors Campaign. 



\section{Bibliography}

[1] American Society of Mechanical Engineers. Section II, Part D (Metric). In ASME Boiler and Pressure Vessel Code. 2015.

[2] American Society of Mechanical Engineers. Section III, Division 5. In ASME Boiler and Pressure Vessel Code. 2017.

[3] Tai Asayama and Yukio Tachibana. Existing Evaluation Procedures for Grade 91 and Hastelloy XR. Technical report, ASME STP-NU-018, 2009.

[4] ASTM International. E 21-09: Standard Test Methods for Elevated Temperature Tension Tests of Metallic Materials, 2009.

[5] J. L. Chaboche. Time-independent constitutive theories for cyclic plasticity. International Journal of Plasticity, 2(2):149-188, 1986.

[6] J. L. Chaboche. Continuum damage mechanics: Present state and future trends. Nuclear Engineering and Design, 105(1):19-33, 1987.

[7] J. L. Chaboche. On some modifications of kinematic hardening to improve the description of ratchetting effects. International Journal of Plasticity, 7(7):661-678, 1991.

[8] J. L. Chaboche. A review of some plasticity and viscoplasticity constitutive theories. International Journal of Plasticity, 24(10):1642-1693, oct 2008.

[9] J. L. Chaboche and G. Cailletaud. On the calculation of structures in cyclic plasticity or viscoplasticity. Computers and Structures, 23(1):23-31, 1986.

[10] J. L. Chaboche and G Cailletaudb. Integration methods for complex plastic constitutive equations. Computational Methods in Applied Mechanics and Engineering, 133(95):125$155,1996$.

[11] Jean-Louis Chaboche. Thermodynamic formulation of constitutive equations and application to the viscoplasticity and viscoelasticity of metals and polymers. International Journal of Solids and Structures, 34(18):2239-2254, 1997.

[12] J.L. Chaboche. Constitutive equations for cyclic plasticty and cyclic viscoplasticity. International Journal of Plasticity, 5:247-302, 1989.

[13] B. K. Choudhary and E. Isaac Samuel. Creep behaviour of modified 9Cr-1Mo ferritic steel. Journal of Nuclear Materials, 412(1):82-89, 2011.

[14] Kalyanmoy Deb, Amrit Pratap, Sameer Agarwal, and T. Meyarivan. A fast and elitist multiobjective genetic algorithm: NSGA-II. IEEE Transactions on Evolutionary Computation, 6(2):182-197, 2002.

[15] F-A. Fortin, F-M. De Rainville, and M-A. Gardner. DEAP: Evolutionary algorithms made easy. Journal of Machine Learning Research, 13:2171-2175, 2012. 
[16] C. O. Frederick and P. J. Armstrong. A mathematical representation of the multiaxial Bauschinger effect. Materials at High Temperatures, 24(1):1-26, 2007.

[17] S Kim and J R Weertman. Investigation of Microstructural Changes in a Ferritic Steel Caused by High Temperature Fatigue. Metallurgical Transactions, 19A(April):999-1007, 1988.

[18] K. Kimura, H. Kushima, and K. Sawada. Long-term creep deformation property of modified 9Cr-1Mo steel. Materials Science and Engineering A, 510-511(C):58-63, 2009.

[19] U .F. Kocks. Kinematics and Kinetics of Plasticity. In U. F. Kocks, C. N. Tome, and H-R Wenk, editors, Texture and Anisotropy, chapter 8, pages 327-389. 1998.

[20] U F Kocks. Realistic constitutive relation for metal plasticity. Materials Science and Engineering A, 317:181-187, 2001.

[21] U. F. Kocks, A. S. Argon, and M. F. Ashby. Thermodynamics and kinetics of slip. In B. Chalmers, J. W. Christian, and T. B. Massalski, editors, Progress in Materials Science, pages 64-291. 1975.

[22] Gyeong H. Koo and Ji Hyun Kwon. Identification of inelastic material parameters for modified 9Cr-1Mo steel applicable to the plastic and viscoplastic constitutive equations. International Journal of Pressure Vessels and Piping, 88(1):26-33, 2011.

[23] Gyeong H. Koo and Jae H. Lee. Investigation of ratcheting characteristics of modified 9Cr-1Mo steel by using the Chaboche constitutive model. International Journal of Pressure Vessels and Piping, 84(5):284-292, 2007.

[24] E. Krempl. Models of viscoplasticity some comments on equilibrium (back) stress and drag stress. Acta Mechanica, 69(1-4):25-42, 1987.

[25] E. Krempl. Creep-Plasticity Interaction. In Creep and Damage in Materials and Structures, pages 285-348. 1999.

[26] S. Latha, M. Nandagopal, S. Panneer Selvi, K. Laha, and M. D. Mathew. Tensile and creep behaviour of modified $9 \mathrm{Cr}-1 \mathrm{Mo}$ steel cladding tube for fast reactor using metallic fuel. Procedia Engineering, 86:71-79, 2014.

[27] Kouichi Maruyama, Junya Nakamura, Kyosuke Yoshimi, and Yuji Nagae. Evaluation of long-term creep rupture life of Gr.91 steel by analysis of on-going creep curves. In Proceedings from the Eighth International Conference on Advances in Materials Technoglogy for Fossil Power Plants, pages 467-478, 2016.

[28] H. Mecking and U. F. Kocks. Kinetics of flow and strain-hardening. Acta Metallurgica, 29:1865-1875, 1981.

[29] H Mecking, B Nicklas, N. Zarubova, and U F Kocks. A "universal" temperature scale for plastic flow. Acta Metallurgica, 34(3):527-535, 1986. 
[30] N. Ohno and J.-D. Wang. Kinematic hardening rules with critical state of dynamic recovery, part I: formulation and basic features for ratchetting behavior. International Journal of Plasticity, 9(3):375-390, 1993.

[31] N. Ohno and J.-D. Wang. Kinematic hardening rules with critical state of dynamic recovery, part II: Application to experiments of ratchetting behavior. International Journal of Plasticity, 9(3):391-403, 1993.

[32] R. W. Swindeman. Cyclic Stress-Strain-Time Response of a 9CMMo-V-Nb Pressure Vessel Steel at High Temperature. In H. D. Solomon, G. R. Halford, L. R. Kaisand, and B. N. Leis, editors, Low Cycle Fatigue, ASTM STP 942, pages 107-122. American Society for Testing and Materials, Philadelphia, 1988.

[33] K. P. Walker and E. Krempl. An implicit functional theory of viscoplasticity. Mechanics Research Communications, 5(4):179-184, 1978.

[34] Yanli Wang, Mark C. Messner, and T.-L. Sham. Report on the fy18 uniaxial material model testing and key feature test articles testing of grade 91. Technical report, 2018.

[35] M. Yaguchi and Y. Takahashi. Unified Inelastic Constitutive Model for Modified 9Cr1Mo Steel Incorporating Dynamic Strain Aging Effect. JSME International Journal, Series A, 42(1):1-10, 1999.

[36] Masatsugu Yaguchi and Yukio Takahashi. Ratchetting of viscoplastic material with cyclic softening, part 1: Experiments on modified 9Cr-1Mo steel. International Journal of Plasticity, 21(1):43-65, 2005.

[37] Masatsugu Yaguchi and Yukio Takahashi. Ratchetting of viscoplastic material with cyclic softening, part 2: application of constitutive models. International Journal of Plasticity, 21:835-860, 2005.

[38] Kuo Zhang and Jarir Aktaa. Characterization and modeling of the ratcheting behavior of the ferritic-martensitic steel P91. Journal of Nuclear Materials, 472:227-239, 2016. 

Development of Grade 91 inelastic model for incorporation in ASME Division 5

July 2018

\section{Distribution List}

$\begin{array}{lll}\text { Name } & \text { Affiliation } & \text { Email } \\ \text { Caponiti, A. } & \text { DOE } & \text { alice.caponiti@nuclear.energy.gov } \\ \text { Gouger, H.D. } & \text { INL } & \begin{array}{l}\text { hans.gougar@inl.gov } \\ \text { cgrandy@anl.gov }\end{array} \\ \text { Grandy, C. } & \text { ANL } & \text { bobhill@anl.gov } \\ \text { Hill, R.N. } & \text { ANL } & \text { gkrumdick@anl.gov } \\ \text { Krumdick, G.K. } & \text { ANL } & \text { sue.lesica@nuclear.energy.gov } \\ \text { Lesica, S. } & \text { DOE } & \text { mli@anl.gov } \\ \text { Li, M. } & \text { ANL } & \text { michael.mcmurtrey@inl.gov } \\ \text { McMurtrey, M. } & \text { INL } & \text { messner@anl.gov } \\ \text { Messner, M.C. } & \text { ANL } & \text { natesan@anl.gov } \\ \text { Natesan, K. } & \text { ANL } & \text { quallsal@ornl.gov } \\ \text { Qualls, A.L. } & \text { ORNL } & \text { ssham@anl.gov } \\ \text { Sham, T.-L. } & \text { ANL } & \text { dsingh@anl.gov } \\ \text { Singh, D. } & \text { ANL } & \text { thomas.sowinski@nuclear.energy.gov } \\ \text { Sowinski, T.E. } & \text { DOE } & \text { wangh@ornl.gov } \\ \text { Wang, H. } & \text { ORNL } & \text { wangy2@ornl.gov } \\ \text { Wang, Y. } & \text { ORNL } & \text { richard.wright@inl.gov } \\ \text { Wright, R. } & \text { INL } & \text { xuanzhang@anl.gov } \\ \text { Zhang, X. } & \text { ANL } & \end{array}$






\section{Argonne}

\section{Applied Materials Division}

Argonne National Laboratory

9700 South Cass Avenue, Bldg. 208

Argonne, IL 60439

www.anl.gov 